\title{
Energy geostructures: Theory and application
}

\author{
Alessandro F. Rotta Loria ${ }^{1, *}$ \\ ${ }^{1}$ Northwestern University, Department of Civil and Environmental Engineering, Mechanics and Energy Laboratory, \\ 2145 Sheridan Road, Evanston, Illinois 60208, USA
}

\begin{abstract}
The subsurface represents space and resource of ever-growing importance to meet human activity needs associated with the availability of built environments and energy. So-called energy geostructures represent a breakthrough technology in this context. By integrating the structural support role of earth-contact structures with the heating-cooling role of shallow geothermal heat exchangers, energy geostructures can sustain or enclose built environments while providing them with renewable thermal energy. Despite such promising features, the integrated roles of energy geostructures pose various challenges to understand their behavior and performance, and to address the related analysis and design. Appropriate formulation and application of scientific theory are crucial for the successful analysis and design of energy geostructures. This Bright Spark Lecture Paper presents selected theory for addressing the behavior and performance of energy geostructures, and discusses the application of this theory to analysis and design. In this context, the work focuses on energy piles and barrettes, energy tunnels, as well as energy walls and slabs. The ultimate goal of this paper is to provide competence for facilitating future research and development of energy geostructures across science and engineering.
\end{abstract}

\section{Introduction}

The integration of multiple roles in technologies to serve human activity needs in a variety of ways is a complex, pressing and fascinating challenge of the present times. For centuries, the role of earth-contact structures, such as foundations, earth retaining structures and other underground structures, has solely been to support the built environment structurally. For decades, the role of shallow geothermal heat exchangers has solely been to supply thermal energy to the built environment. So-called energy geostructures combine the role of the structural support with the role of the thermal energy carrier in a unique technology to serve all types of buildings and infrastructure [1]. All earth-contact structures that embed a piping circuit with a circulating heat carrier fluid to achieve a heat exchange between the ground and any building or infrastructure represent energy geostructures. In this way, conventional pile foundations, tunnels, walls, slabs, and other underground structures, become novel energy pile foundations, energy tunnels, energy walls, etc.

Over the past twenty years, increasing interest has been concentrated on energy geostructures. This interest has been motivated by the fact that 30 to $40 \%$ of the final energy consumption of developed and developing countries is associated with the building sector, whose thermal energy requirements for space heating and cooling as well as hot water account from 50 to $80 \%$ of the total end-use of energy [2]. By harvesting renewable geothermal energy from the ground through earth-contact structures that would have been built anyway to support buildings and infrastructures, energy geostructures represent an advantageous technology to meet the thermal energy requirements of the building sector sustainably. Through a continuous energy supply, which can be achieved everywhere on Earth, irrespective of the weather as well as of the local geological conditions, the harvesting of renewable geothermal energy allows limiting the historical use of non-renewable energy sources. In turn, this approach positively influences the natural environment. Through the embedment of pipes in structural elements, the construction of energy geostructures allows limiting land use and lowering construction costs compared to conventional shallow geothermal heat exchangers. By representing local sources of renewable energy, energy geostructures can thus uniquely develop carbon-neutral buildings and infrastructure, meeting international directives and standards that foster this critical change for the built and natural environments $[3,4]$.

Despite such promising features, the integrated roles of energy geostructures pose various challenges linked to the understanding of their behavior and performance, and the related analysis and design. The formulation of adequate scientific theory - validated with experimental data - and its application via suitable approaches and methodologies are crucial for the successful analysis and design of energy geostructures.

Looking at such a challenge, this Bright Spark Lecture Paper presents theory that can serve the understanding of the behavior and performance of energy geostructures and discusses its application to analysis and design. Focusing on energy piles and barrettes, energy tunnels, and energy

\footnotetext{
* Corresponding author: af-rottaloria@northwestern.edu
} 
walls and slabs, this paper specifically has the three following objectives:

a) To present a summary of the challenges involved with the analysis and design of energy geostructures.

b) To summarize available theory to describe energy, geotechnical and structural aspects governing the behavior and performance of energy geostructures.

c) To discuss the advantages and the limitations involved with the application of available theory to the analysis and design of energy geostructures.

A comprehensive treatment of the theoretical essentials and practical application of the analysis and design of energy geostructures has been recently published [1] together with detailed state-of-the-art publications [5-9]. In this context, this paper is deliberately restricted in scope not to duplicate information. Specifically, this work is written with the primary aim to represent an opportunity to reflect on how the scientific theory developed in the field of energy geostructures over the past two decades can contribute to applications in engineering.

This paper thus provides a complementary overview to available competence about energy geostructures for the international scientific and engineering arenas. This perspective might be especially relevant to individuals who takle energy geostructures for the first time or master specific aspects of this subject.

\section{Challenges}

\subsection{Interdisciplinary aspects}

\subsubsection{General}

A crucial challenge that arises when dealing with energy geostructures is the necessity of multidisciplinary competence to appreciate the behavior, performance and related capabilities of such technology fully. Energy geostructures can serve built environments from the building to the district and city scales. In this context, focusing on the analysis and design of energy geostructures within the broader design process of construction technologies, competence is needed in energy engineering and building science, structural, geotechnical, and mechanical engineering, architecture, urban planning and project management.

The focus of this work is on competence pertaining to the field of energy, structural and geotechnical engineering. Three interconnected aspects of the behavior, performance and capabilities of energy geostructures are addressed in the following (Fig. 1):

1) Energy aspects;

2) Structural aspects;

3) Geotechnical aspects.

\subsubsection{Energy aspects}

Addressing energy aspects is crucial to assess the amount of energy that energy geostructures can transfer over time (e.g., from the ground to buildings and infrastructure or vice versa). These aspects dictate the result of the relative competitiveness between energy geostructures and other energy systems (e.g., in terms of performance, return of investment and environmental benefits).

Theory is available to assess energy aspects governing the behavior and performance of conventional shallow geothermal heat exchangers (e.g., geothermal boreholes). However, new developments have been proposed and are still necessary to address energy aspects governing energy geostructures. This need is corroborated by the different features characterizing energy geostructures compared to conventional shallow geothermal heat exchangers, such as their geometry and constituting materials. These features require tailored theoretical models and methods for energy analysis and design purposes.

\subsubsection{Structural aspects}

Considering structural aspects is critical to ensure the durability and resilience of energy geostructures and superstructures due to the actions involved. These aspects dictate the possible modifications to the structural design of any project for ensuring specific requirements.

Theory is available to assess structural aspects governing the behavior and performance of conventional geostructures (e.g., pile foundations, slabs, walls and tunnels). However, new developments have been proposed and are still necessary to address structural aspects governing energy geostructures. This need is corroborated by the combined application of mechanical and thermal loads due to the integrated structural support and geothermal heat exchanger roles of energy geostructures, respectively. The unprecedented effects involved by the combined application of such loads, as compared to the effects caused by the only mechanical loads applied to conventional geostructures, require modified and novel theoretical models and methods for structural analysis and design purposes. Imposed forces or displacement that result from permanent, variable, or other forms of mechanical loads are applied to energy geostructures together with temperature variations.

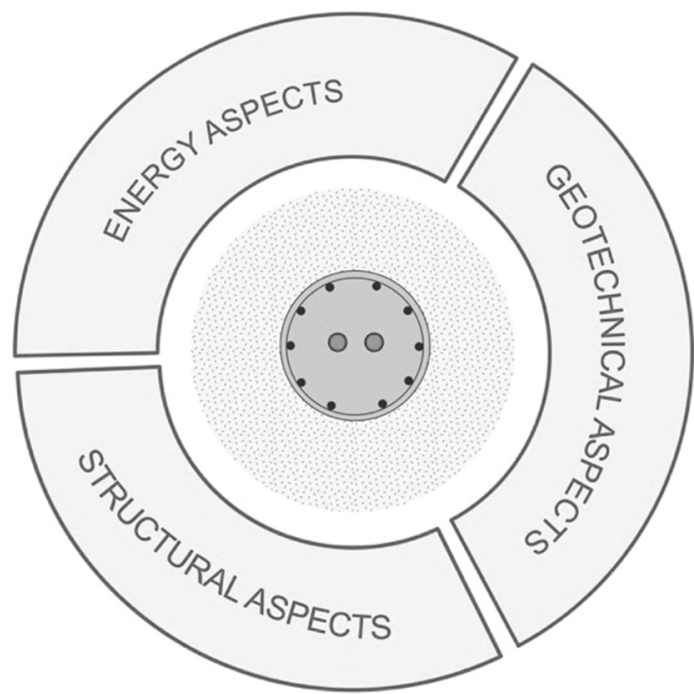

Fig. 1: Key aspects to consider in the analysis and design of energy geostructures. 


\subsubsection{Geotechnical aspects}

Tackling geotechnical aspects is essential to ensure that adequate deformation and stability of energy geostructures hold over the lifetime of the project. These aspects can involve modifications to any design process together with energy and structural aspects.

Theory is available to assess geotechnical aspects governing the behavior and performance of conventional geostructures. However, new developments have been proposed and are still necessary to address geotechnical aspects governing energy geostructures. Again, this need results from the combined application of mechanical and thermal loads, which involve unprecedented effects for the ground and the energy geostructures.

\subsubsection{The role of scientific theory}

All of the previous aspects are interconnected, markedly influencing the design process of energy geostructures. Consideration of these aspects may occur at different stages of the design process but must eventually be addressed as a whole for ensuring adequate performance of energy geostructures. Indeed, consideration of energy, structural and geotechnical aspects characterizing the behavior and performance of energy geostructures should resort to appropriate scientific theory and application of this theory via adequate approaches and methodologies.

\subsection{Multiphysical phenomena}

\subsubsection{General}

Another significant challenge involved with energy geostructures is the need to cope with multiphysical phenomena (e.g., thermal, hydraulic and mechanical). Heat transfers, mass transfers and deformations constitute the core of this challenge, controlling the behavior and performance of energy geostructures [1].

Heat transfer, mass transfer and deformation phenomena are caused by perturbations of the physical equilibrium characterizing systems that involve energy geostructures. By impacting the engineering qualities (e.g., properties and behavior) of the involved materials, heat transfers, mass transfers and deformations influence the response of energy geostructures (e.g., energy, geotechnical and structural). Typical sources of perturbations for the equilibrium of energy geostructures are the mechanical loads arising from their structural support role and the thermal loads associated with their energy transfer role [e.g., 10]. Due to these perturbations, flows of heat and mass take place together with expansions and contractions of the materials constituting the energy geostructures and the ground. Therefore, the origin of these phenomena can be, in many instances, mechanically and thermally induced.

\subsubsection{Peculiarities of heat transfer, mass transfer and} deformation in the context of energy geostructures

Heat mainly flows by conduction and convection in most problems involving energy geostructures [e.g., 11]. Convection governs the heat flow of the fluid circulating in the pipes of energy geostructures (e.g., water with or without glycol), the heat flow in the ground in the presence of groundwater flow, and the heat flow in underground built environments adjacent to energy geostructures due to airflows (e.g., parking garages, as well as metro and road tunnel spaces). Conduction dominates the heat flow across the walls of the pipes embedded within energy geostructures, the material constituting such geostructures (e.g., reinforced concrete) and the ground (e.g., soil or rock) unless groundwater flow is present. A schematic of the modes of heat transfer involved with energy geostructures is reported in Fig. 2.
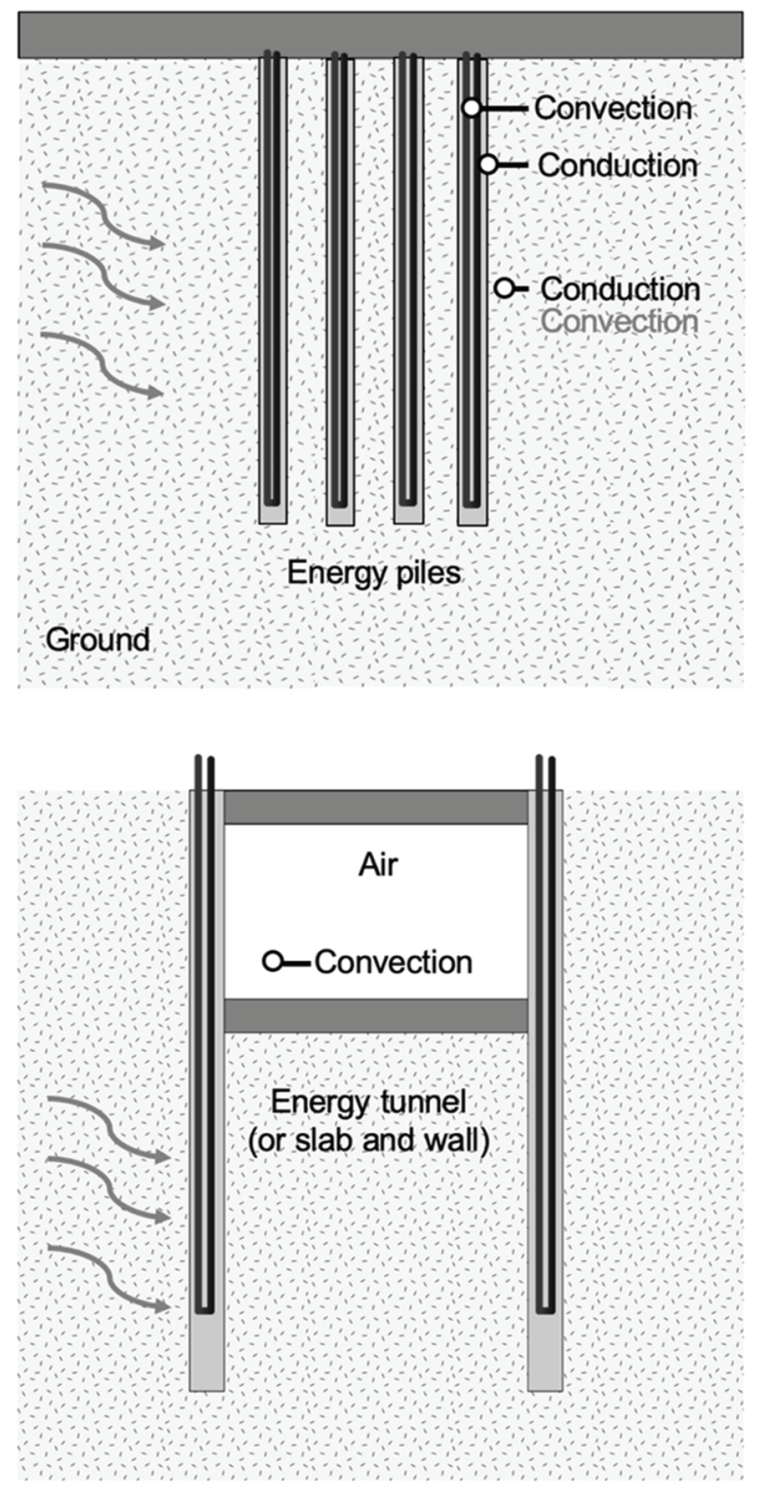

Fig. 2: Modes of heat transfer involved with energy geostructures.

Thermal insulation between energy geostructures and underground built environments allows minimizing, upon willingness, the heat transferred by convection with such environments. A schematic illustrating this approach is reported in Fig. 3. 
Detail A
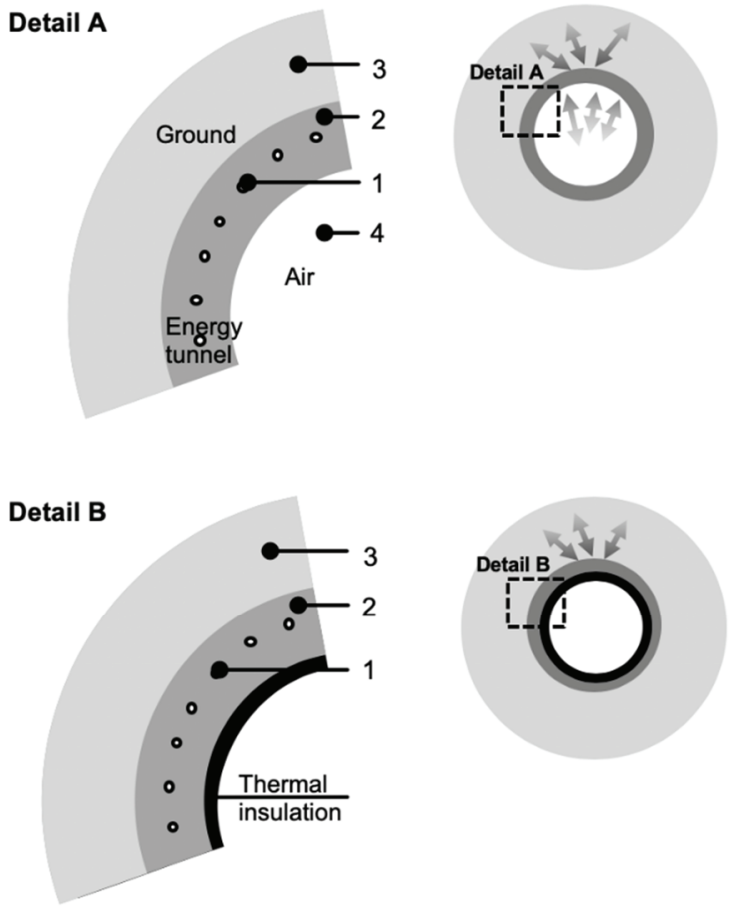

\section{Legend}

1) Convection in the heat carrier fluid circulating in the pipes

2) Conduction across the pipe wall and within the concrete

3) Conduction and/or convection in the ground

4) Convection at the air-concrete interface

Fig. 3: Possible modes of heat transfer in energy geostructures embedding underground built environments.

Mass, in the form of air, can flow under turbulent or laminar conditions in underground built environments adjacent to energy geostructures, depending on the velocity of the flow and the size of the environment wherein the flow occurs [e.g., 12]. Airflows are generally turbulent for even relatively limited values of airflow velocity in underground tunnels due to their large diameters [e.g., 13]. Airflows may be considered laminar in underground parking garages for the usual minimal airflow velocities present therein. Mass, in the form of groundwater, typically flows under laminar conditions in the pores of the concrete, soil and rock [e.g., 14].

Deformation develops under quasi-static conditions due to the influence of mechanical and thermal loads applied to energy geostructures. Compression mechanical loads result in mechanically induced contractions of the concrete constituting energy geostructures and the surrounding ground [e.g., 10]. Tensile mechanical loads cause mechanically induced expansions [e.g., 15]. Heating thermal loads result in thermally induced expansions of the concrete constituting energy geostructures [e.g., 10,16-18]. Cooling thermal loads generate thermally induced contractions of the concrete [e.g., 19]. Restraint of thermally induced expansions results in compressive stresses [e.g., 20,21]. Restriction of thermally induced contractions causes reductions in compressive stresses. Such reductions in compressive stresses can lead to tensile stresses in systems subjected to low compressive stresses due to mechanical loads [e.g., 22]. Notably, heating thermal loads can cause both expansions and contractions of soils, the latter phenomenon being often termed heating induced contraction [e.g., 23-32]. Cooling thermal loads are generally recognized only to generate contractions of soils. A schematic of the deformation caused by mechanical and thermal loads applied to energy geostructures is reported in Fig. 4.

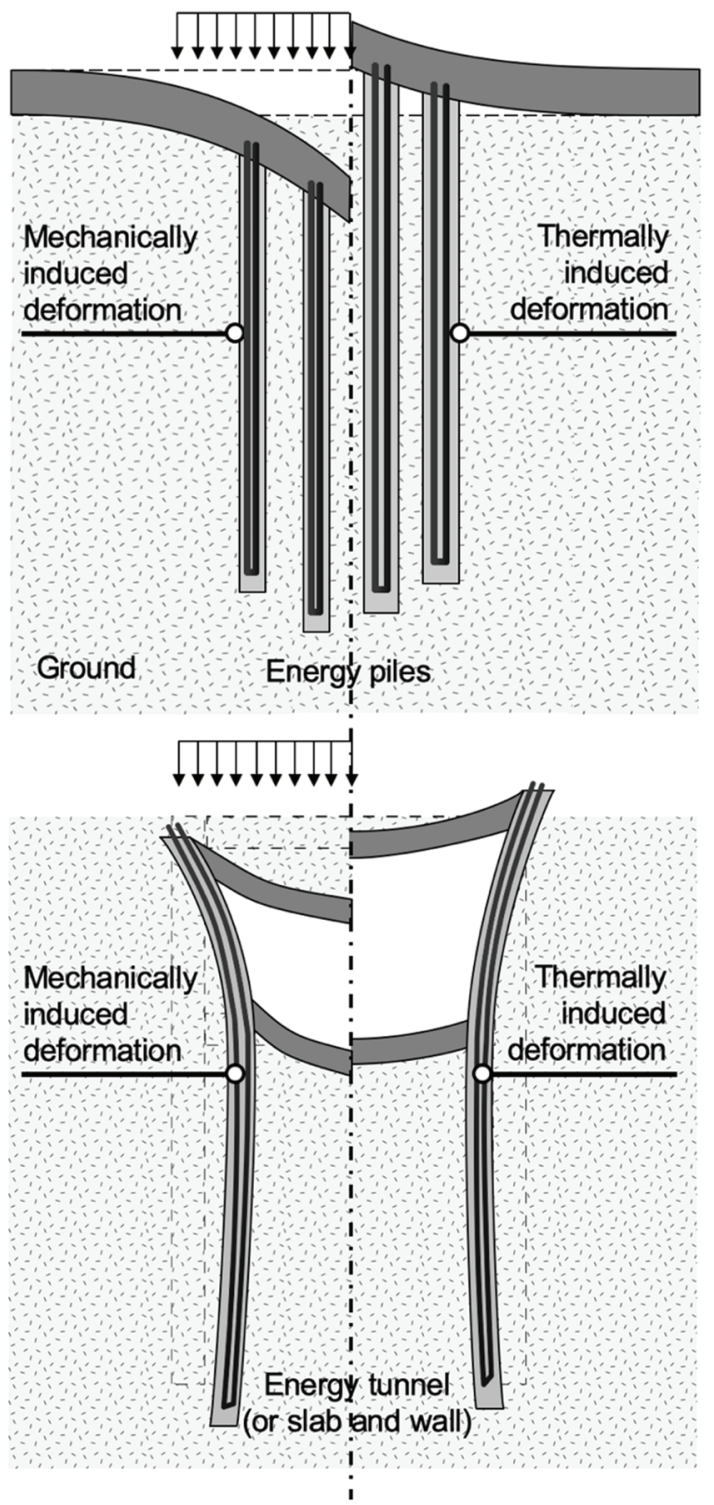

Fig. 4: Deformations characterizing energy geostructures subjected to mechanical and thermal loads. The schematic for thermal loading refers to positive temperature variations.

\subsubsection{Relevant couplings}

All of the phenomena involved with energy geostructures are interconnected (i.e., coupled) [1]. In other words, heat transfer can cause mass transfer and deformation, all of the other combinations being true (Fig. 5 (a)). Rigorous 
analyses and designs of energy geostructures are to address all of these couplings. However, simplifications of such physical problems, which already represent an idealization of reality (in principle, other physical phenomena can be investigated), are often made for practical convenience. When developed with judgment, these simplifications lead to realistic results of analysis and design calculations.

A typical approach to model the thermal (T), hydraulic $(\mathrm{H})$ and mechanical $(\mathrm{M})$ phenomena governing energy geostructures (i.e., heat transfer, mass transfer and deformation, respectively) considers mutual influences between thermal and hydraulic phenomena $(\mathrm{T} \leftrightarrow \mathrm{H})$, and between hydraulic and mechanical phenomena $(\mathrm{H} \leftrightarrow \mathrm{M})$, but a one-way influence between thermal and mechanical phenomena $(\mathrm{T} \rightarrow \mathrm{M})$ [6]. In other words, it is considered that heat and mass transfers, as well as mass transfer and deformation, can influence each other, while heat transfer can affect deformation, but not the opposite (Fig. 5 (b)).

A simpler approach to model the thermal, hydraulic and mechanical phenomena is to address, through separate analyses, on the one hand, mutual influences between thermal and hydraulic phenomena $(\mathrm{T} \leftrightarrow \mathrm{H})$, while on the other hand, a one-way influence between thermal and mechanical phenomena $(\mathrm{T} \rightarrow \mathrm{M})$ [1] (Fig. 5 (c)).

Modeling of the previous phenomena resorts to the resolution of appropriate balance and constitutive equations, together with the boundary and initial conditions. In this context, the coupling between the addressed phenomena can be established by linking the fundamental governing variables (e.g., temperature for heat transfer, pressure for mass transfer and material(s) displacement for deformation). This coupling may also resort to physical influences for the material properties (for example, a temperature dependence for the properties of water and air, or soil and concrete). Extensive treatment of this subject is covered elsewhere [1].
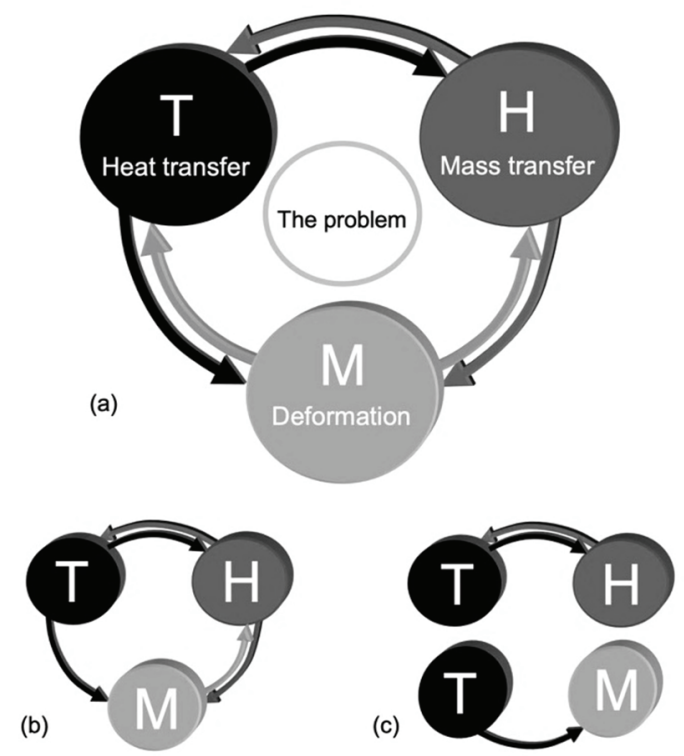

Fig. 5: Idealization of the couplings involved in problems that characterize energy geostructures: (a) rigorous approach; (b) simplified approach; and (c) the simplest approach.

\subsection{Time and length scales}

The time and length scales involved in problems of energy geostructures are broad. A comprehensive understanding of the behavior and performance of energy geostructures results from consideration of these scales. Relevant time scales of phenomena characterizing energy geostructures typically vary from hours to days, commonly are of weeks and years, and can extend to decades. Relevant length scales are typically confined to the macroscopic scale of the materials constituting energy geostructures, the geostructures themselves, as well as the buildings, districts and cities they serve. Nevertheless, information from the microscopic and nanoscopic scales (e.g., describing the constituents of materials) can be significant. Information about the length scale of districts and cities is relevant only for large scale applications addressed by systems of energy geostructures. Scarcely addressed in the past, these large scales are becoming increasingly important.

Scientific theory must be able to address the previous time and length scales through adequate formulations and applications. This ability is critical to achieving a full understanding of the behavior and performance of energy geostructures from energy, structural and geotechnical perspectives for analysis and design purposes.

\subsection{Summary}

Multidisciplinary competence is needed to address the analysis and design of energy geostructures. Consideration of a variety of interconnected phenomena that govern the behavior and performance of energy geostructures exemplifies such a statement. Various time and length scales need to be addressed. Scientific theory based on fundamental principles is vital to resolve these challenges through its adequate application.

\section{Analysis and design approaches}

\subsection{General}

A categorization of the analysis and design approaches for energy geostructures can be made by considering the features of the theory employed (Table 1). This idea and categorization were initially presented by Poulos [33] for the analysis and design of conventional pile foundations. It is expanded hereafter for energy geostructures drawing from the considerations developed by Laloui and Rotta Loria [1].

\subsection{Category 1 approaches}

Category 1 analysis and design approaches are characterized by a purely empirical nature. These approaches were often used for the analysis and design of conventional geostructures [33]. However, they may be considered of little value and applicability for energy geostructures due to the higher complexity of the problems involved [1]. 
Table 1: Analysis and design approaches for energy geostructures depending on the features of the theory employed (modified after Poulos [33] and Laloui and Rotta Loria [1]).

\begin{tabular}{|c|c|c|}
\hline Category & Subdivision & Features \\
\hline 1 & - & $\begin{array}{l}\text { Empirical }- \text { not based on } \\
\text { theoretical principles }\end{array}$ \\
\hline \multirow[t]{2}{*}{2} & $2 \mathrm{~A}$ & $\begin{array}{l}\text { Based on simplified theory or } \\
\text { charts - amenable to hand } \\
\text { calculation }\end{array}$ \\
\hline & $2 \mathrm{~B}$ & $\begin{array}{l}\text { As for } 2 \mathrm{~A} \text {, but theory is more } \\
\text { advanced }\end{array}$ \\
\hline \multirow[t]{3}{*}{3} & $3 \mathrm{~A}$ & $\begin{array}{l}\text { Based on theory - require the } \\
\text { use of a computer }\end{array}$ \\
\hline & $3 \mathrm{~B}$ & $\begin{array}{l}\text { As for } 3 \mathrm{~A} \text {, but accounting for } \\
\text { more complex features in a } \\
\text { simplified manner }\end{array}$ \\
\hline & $3 \mathrm{C}$ & $\begin{array}{l}\text { As for } 3 \mathrm{~A} \text {, but accounting for } \\
\text { more complex features in a } \\
\text { rigorous manner }\end{array}$ \\
\hline
\end{tabular}

\subsection{Category 2 approaches}

Category 2 analysis and design approaches have a proper theoretical basis, often resort to the use of charts, generally involve significant simplifications and may be considered the most used in the engineering practice [1]. The charts available in this category of approaches typically result from calculations of category 3 .

The theory developed for addressing energy aspects in category 2 approaches typically involves simplifications for the thermo-hydraulic behavior of heat exchanger(s), if any heat exchanger is actually modeled. Charts constitute category 2A approaches. Analytical models considering one-dimensional geometries for the energy geostructures constitute category 2B approaches: for example, the behavior of slender cylindrical heat exchangers, such as energy piles, is addressed by considering an infinite linear heat source; similarly, the behavior of plane heat exchangers, such as energy walls and slabs, is tackled by considering an infinite plane heat source.

The theory developed for addressing structural and geotechnical aspects in this category involves simplifications for the thermo-mechanical behavior of the ground. Charts referring to energy geostructures in an idealized ground with a linear elastic behavior characterize category $2 \mathrm{~A}$ approaches (i.e., the ground is considered insensitive to temperature variations and often modeled as a solid continuum without any water in its pores). Analytical models considering energy geostructures embedded in the ground with a non-linear elastic or elasto-plastic behavior characterize category $2 \mathrm{~B}$ approaches. In either of these categories, concrete behavior is typically assumed as linear thermo-elastic.

\subsection{Category 3 approaches}

Category 3 analysis and design approaches typically have a comprehensive theoretical basis and require the use of a computer to serve numerical and analytical methods [1]. The considered approaches are generally used for increasingly advanced analysis and design purposes.
Category 3 approaches typically address the actual time-dependence involved with the operation of energy geostructures and the three-dimensional character of such problems. In this way, a more advanced assessment of the behavior and performance of energy geostructures is achieved, with implications for both the investigation of energy aspects as well as structural and geotechnical aspects of energy geostructures.

The theory serving category 3 approaches can address heat transfer, mass transfer and deformation phenomena over seasonal, monthly, daily and hourly time scales. This feature differs from category 2 approaches that commonly address such phenomena under steady conditions.

From the perspective of energy aspects, the theory serving category 3 approaches accounts for the thermohydraulic interactions between energy geostructures, the actual pipe(s) configuration and the possible presence and influence of groundwater flow. These features are typically addressed in increasingly rigorous ways in category $3 \mathrm{~A}, 3 \mathrm{~B}$ and $3 \mathrm{C}$ approaches. Often, category $3 \mathrm{~A}$ approaches resort to analytical models applied with simple computer programs (e.g., calculation sheets) to address relatively elaborated problems involving energy geostructures compared to those targeted via hand calculations. Category $3 \mathrm{~B}$ and $3 \mathrm{C}$ approaches generally resort to numerical simulations.

From the perspective of structural and geotechnical aspects, the theory serving category 3 approaches can account for a linear elastic or thermo-elastic behavior of the ground, but also more advanced thermo-elastic, plastic or thermo-elastic, thermo-plastic behaviors. In general, the behavior of reinforced concrete is still represented as linear thermo-elastic. Category 3A approaches again typically resort to analytical models applied with simple computer programs (e.g., calculation sheets) to address mechanical interactions and influence between and around energy geostructures. Category $3 \mathrm{~B}$ and $3 \mathrm{C}$ approaches typically resort to numerical simulations. In this way, increasingly advanced aspects of soil behavior, as well as the influence of structural elements connected to energy geostructures, are modeled. Again, this feature differs from category 2 approaches that typically neglect or consider only approximately these features.

\subsection{Considerations}

Category 2 approaches are to date the most diffused ones to address the analysis and design of energy geostructures in practice. Two reasons are considered to facilitate this approach: (1) the expertise that is required to address more advanced categories of analysis and design approaches (i.e., category 3); and (2) the advanced numerical software that are usually required to address these categories of analysis and design.

Various potential energy geostructure installations do not see the light because their potential is thought unsatisfactory during preliminary phases of analysis and design based on inappropriate considerations. Typically, these considerations lead to unprofitable solutions from the standpoint of the payback period of the energy system or unnecessary and unjustified alarming considerations 
from structural and geotechnical perspectives. As an example, the energy potential of energy geostructures is often determined by multiplying values of thermal power per unit length or surface by the dimensions of energy geostructures. This calculation is done with limited consideration of the specific site conditions, the pipe configurations and connections, the flow conditions, the characteristics of the heat pumps, as well as other features that govern the energy yield of energy geostructures. These types of analysis and design, especially when considered fully representative of the energy potential of energy geostructures instead of preliminary, are detrimental to the actual understanding of their energy performance and capabilities. From a broader perspective, this approach restrains the diffusion of energy geostructures worldwide. It should only be used for initial considerations to be enriched with more detailed investigations.

Experience suggests that adequately developed analyses and designs of energy geostructures result in feasible and profitable applications in most of the conditions that are likely to be encountered in practice. Yet, while the combined influence of mechanical and thermal loads must be addressed in any and all projects $[1,34,35]$, it is rare to incur in need to modify the structural or geotechnical design of energy geostructures due to the novel influence of thermal loads. Appropriate use of theory is critical to assess all of these facts.

\subsection{Summary}

Scientific theory represents the basis for a variety of analysis and design approaches for energy geostructures. These approaches span from hand calculations to computer simulations of increasing complexity and rigor. A reasonable compromise between excessive complexity and unacceptable simplicity can be found for any stage of analysis and design. Inadequate investigations can prevent: (i) the assessment of the actual behavior, performance and capabilities of energy geostructures during the analysis and design phases; and (ii) the achievement of the targeted requirements during the operation and management phase.

\section{Analytical frameworks}

\subsection{General}

Analytical frameworks based on simplified theoretical models allow an effective understanding of the role of crucial variables for the behavior and performance of energy geostructures. Application of analytical models is usually more effective than numerical models, because it resorts to hand calculations instead of computer simulations that can be particularly time-consuming. However, results of analytical calculations are generally inferior in rigor to numerical simulations and can address simpler problems. Focus is given herafter to analytical models and methods addressing energy, geotechnical and structural aspects of energy geostructures.

\subsection{Energy aspects}

4.2.1 Available investigation methods

The analytical investigation of energy aspects characterizing energy geostructures can be achieved through the use of:

1) Thermal power charts;

2) Thermal resistance models;

Thermal power charts serve category $2 \mathrm{~A}$ analysis and design approaches. Thermal resistance models typically serve category $2 \mathrm{~B}$ approaches. They also serve category $3 \mathrm{~A}$ approaches when applied through a computer for addressing relatively advanced problems, such as the analysis of the thermal interactions between multiple energy geostructures (e.g., instead of the investigation of the thermal response of a single energy geostructure).

These methods find their roots in developments for conventional shallow geothermal heat exchangers, such as borehole heat exchangers. Particularly when considering thermal resistance models, various formulations developed for vertical geothermal borehole heat exchangers are applied to energy piles. However, borehole heat exchanger and energy piles differ in several features, including slenderness ratio, bluffness and heat capacity [e.g., 1,5,9]. Therefore, the available theory for borehole heat exchangers must be applied with caution to energy piles, similar to other formulations available that may apply to relevant energy geostructures.

\subsubsection{Thermal power charts}

Charts allowing to estimate the thermal power that can be extracted or injected from energy geostructures are available for energy piles [e.g., 36,1], energy walls [e.g., 37,38] and energy tunnels [e.g., 39,1,40]. These charts account for site characteristics that include the pipe configuration, the effective thermal conductivity of the ground, the presence, significance and direction of groundwater flow, and the presence and significance of the airflow in underground built environments. An example of a thermal power chart proposed by Laloui and Rotta Loria [1] for energy tunnels characterized by different airflow conditions is reported in Fig. 6.

These charts can be useful to gather preliminary information on the energy potential of given energy geostructure installations. They may be considered to yield conservative estimations of thermal power because referring to energy operations under steady-flux conditions (i.e., associated with lower bounds of the actual values of thermal power that can be harvested under dynamic conditions). Nevertheless, no energy analysis or design should be considered complete without a thorough investigation of the actual behavior and performance of energy geostructures across the relevant time scales. A justification for this consideration is that, while these charts provide values of thermal power, it is generally essential to determine the thermal energy that energy geostructures can provide depending on the enduses of the buildings or infrastructure they serve. 


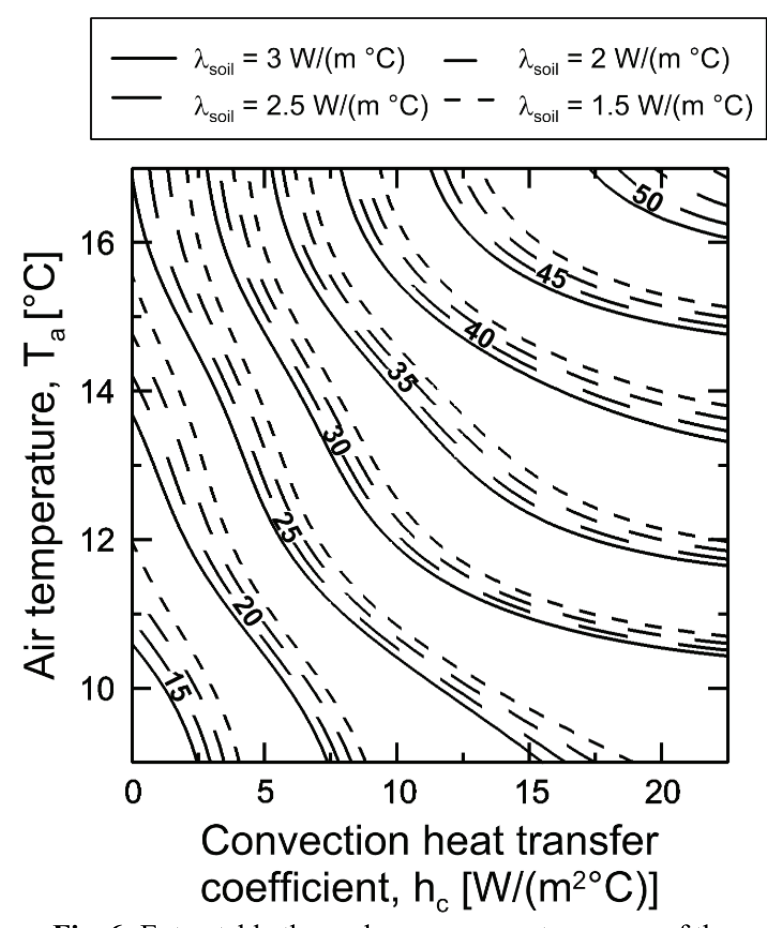

Fig. 6: Extractable thermal power per meter square of the active surface of energy tunnels for different airflow conditions (modified after Laloui and Rotta Loria [1]). The values on the contour lines represent the harvestable thermal power while

$\lambda_{\text {soil }}$ is the effective thermal conductivity of the ground.

\subsubsection{Thermal resistance models}

A more advanced analytical method to address energy aspects involved with energy geostructures resorts to the concept of thermal resistance. This concept has marked utility in solving relatively complex heat transfer problems [41]. It takes different forms for different modes of heat transfer and usually includes the influence of the geometry of the heat exchanger [5]. A general formulation of thermal resistance reads

$$
R_{t h}=\frac{\Delta T}{\dot{Q}}=\frac{\Delta T}{\dot{q}_{i} A}
$$

where $\Delta T$ is the relevant temperature variation and $\dot{Q}$ is the thermal power, $\dot{q}_{i}$ is the heat flux density of the relevant mode of heat transfer (e.g., conduction or convection) and $A$ is the surface normal to heat transfer.

Considering reference times $t^{*}$ allows developing useful considerations for the analysis of heat transfer through the concept of thermal resistance [1]. For time intervals $t \leq t^{*}$, the heat transfer within a considered body (e.g., an energy geostructure) cannot be associated to steady conditions and requires a time-dependent modelling approach to be described. In contrast, for time intervals $t>t^{*}$, the heat transfer within a considered body can be associated with steady conditions and can be meaningfully described with a time-independent modeling approach. In general, for $t>t^{*}$, steady-flux conditions (not steady-state conditions [42]), characterize the heat transfer within a considered body.

When the previous approach is considered to address the heat transfer characterizing an energy geostructure, for $t>t^{*}$ the global heat transfer within and around such geostructure can be simplified in one time-independent process and one time-dependent process, respectively. Mathematically, these processes are associated with a time-independent and time-dependent thermal resistance, yielding a total thermal resistance that reads

$$
R_{T}(t) \equiv R_{t h}=R_{g h e}+G_{f}\left(x_{i}, t\right)
$$

where $R_{T}(t)$ is the total thermal resistance, $R_{\text {ghe }}$ is the time-independent part of the total thermal resistance (coinciding with the thermal resistance of the geothermal heat exchanger), and $G_{f}\left(x_{i}, t\right)$ is the time-dependent part of the total thermal resistance, often called G-function (with $x_{i}$ the coordinates of a considered point and $t$ the time). Equation (2) should be applied to investigate heat transfer problems for time scales $t>t^{*}=t_{\text {ghe }}$, where $t_{g h e}$ is the characteristic time of the geothermal heat exchanger. The time $t_{g h e}$ varies for different energy geostructure geometries [1]. The approach of expressing the total thermal resistance as in equation (2) draws from the work of Li and Lai [42]. Although G-functions have initially been expressed in dimensionless forms for conventional geothermal heat exchangers [43-45], they have here the same unit measure of thermal resistance and express the temperature response in the ground due to a unit-step change in heat transfer rate $\dot{Q}$ [42].

An alternative expression of equation (2) is as follows

$$
\dot{Q}=\dot{q}_{i} A=\frac{\bar{T}_{f}(t)-T_{0}}{R_{T}(t)}=\frac{\bar{T}_{f}(t)-T_{0}}{R_{g h e}+G_{f}\left(x_{i}, t\right)}
$$

where $\bar{T}_{f}(t)$ is the average temperature of the heat carrier fluid circulating in the pipes of the energy geostructure and $T_{0}$ is the initial temperature (e.g., of the ground). Through equation (3), two aspects governing the energy operation of energy geostructures can be addressed [42]:

a) What the heat transfer rate of the energy geostructure as a function of time is, given a particular temperature difference between the circulating fluid and the ground.

b) What the temperature difference as a function of time is, given a required heat exchange rate.

When problem (a) is considered, the term $\bar{T}_{f}(t)-T_{0}$ is known, and $R_{g h e}$ and $G_{f}\left(x_{i}, t\right)$ need to be determined to estimate $\dot{Q}$. When problem (b) is considered, the term $\dot{Q}$ is known, and $R_{g h e}$ and $G_{f}\left(x_{i}, t\right)$ need to be determined for estimating $\bar{T}_{f}(t)$. Once $\bar{T}_{f}(t)$ is known, the inlet temperature of the fluid, $\bar{T}_{f, i n}(t)$, and the outlet temperature of the fluid, $\bar{T}_{f, \text { out }}(t)$, can be calculated. In many cases, it is assumed that $\bar{T}_{f}(t)=\left[\bar{T}_{f, i n}(t)+\right.$ $\left.\bar{T}_{f, \text { out }}(t)\right] / 2$ [46]. Therefore, the inlet and outlet fluid temperatures can be computed as [42] 


$$
\left\{\begin{array}{l}
\bar{T}_{f, \text { in }}(t)=\bar{T}_{f}(t)+\frac{\dot{Q}}{2 \rho_{f} c_{p, f} \dot{V}} \\
\bar{T}_{f, \text { out }}(t)=\bar{T}_{f}(t)-\frac{\dot{Q}}{2 \rho_{f} c_{p, f} \dot{V}}
\end{array}\right.
$$

where $\rho_{f}$ and $c_{p, f}$ are the density and specific heat of the heat carrier fluid circulating in the pipes, respectively, and $\dot{V}$ is the volumetric flow rate. Equation (4) can be equivalently expressed as

$$
\begin{gathered}
\dot{Q}=\rho_{f} c_{p, f} \dot{V}\left(\bar{T}_{f, \text { in }}(t)-\bar{T}_{f, \text { out }}(t)\right) \\
=\dot{m} c_{p, f} \Delta T
\end{gathered}
$$

where $\dot{m}$ is the mass flow rate of the circulating heat carrier fluid in the pipes.

Various thermal resistances developed for conventional shallow geothermal heat exchangers can serve, as appropriate, analytical investigations of both cylindrical and plane energy geostructures. Details of these solutions, which include both time-independent and time-dependent formulations of thermal resistances, are reported elsewhere $[47,1,7,5]$. Specific thermal resistances have been proposed for energy piles to overcome limitations of conventional solutions developed for vertical borehole heat exchangers [e.g., 48-50]. Complementary analytical solutions have been developed for energy walls [e.g., 51-54] and tunnels [e.g., 55,56].

\subsection{Structural aspects}

\subsubsection{Available investigations methods}

The analytical investigation of structural aspects characterizing energy geostructures can be achieved through the use of:

1) Stress charts;

2) Continuum analysis models;

3) Load-transfer models;

Stress charts serve category $2 \mathrm{~A}$ analysis and design approaches. Continuum analysis models serve category 2B approaches. Load-transfer models serve category $3 \mathrm{~A}$ or even 3B approaches.

Similar to the analytical investigation of energy aspects involved with the operation of energy geostructures, the aforementioned methods find roots in earlier developments for conventional geostructures. In this context, extensions and modifications of the previously available theory have been motivated by the unprecedented influence of thermal loads on the deformation of energy geostructures, which are to be superimposed to mechanical loads.

\subsubsection{Stress charts}

A variety of charts provide estimations of the vertical stress that are likely to develop in energy piles due to thermal loads [e.g., 57-61] and mechanical loads [e.g., 62-65]. These charts are typically based on results of load-transfer investigations or finite element simulations.
Initially developed for conventional piles subjected to only mechanical loads, various stress charts have been developed for energy piles subjected to thermal loads. These charts provide estimations of vertical stress for variables that include different ground and geostructure properties, as well as structural restraints. The relevance of estimating the vertical stress characterizing energy geostructures, such as energy piles, barrettes, walls and slabs, is that the considered variable needs to be controlled for ensuring the required structural performance. Comparable considerations apply to the hoop stress developed in energy tunnels.

\subsubsection{Continuum analysis models}

More advanced analysis methods than charts draw from simplifications of the thermo-elastic continuum theory (e.g., treating one-dimensional conditions). Two analytical frameworks tackle the influence of thermal loads on structural aspects characterizing energy geostructures such as energy piles $[10,20,21]$ and energy walls and slabs [66]. These frameworks are reported hereafter, considering compressive stresses, contractive strains and downward displacements as positive.

Thermal loads are associated with temperature variations within and around energy geostructures. These variations are usually non-uniform and can be idealized as composed of two contributions: a constant distribution of temperature variation, $\Delta T_{a}$, inducing an axial strain, and a linear distribution of temperature variation, $\Delta T_{c}$, causing a curvature. Constant distributions of temperature variations are considered alone when addressing the analytical modeling of cylindrical energy geostructures. Constant and linear distributions of temperature variations are considered together when addressing the analytical modeling of plane energy geostructures. Prevention of these thermally induced effects results in axial loads and bending moments, respectively [66].

Mechanical actions are associated with forces and displacements applied to energy geostructures. The effects of these forces and displacements are axial and transversal displacements, neutral axis rotations, shear forces and bending moments.

The concept of degree of freedom can effectively address some significant effects caused by temperature variations applied to energy geostructures, such as the development of internal forces and bending moments. In essence, this concept links the development of a relevant physical quantity to its value under free thermal deformation conditions. In the following, this concept is used to address axial and flexural effects caused by thermal actions applied to energy geostructures.

A constant distribution of temperature variation, $\Delta T_{a}$, applied to an energy geostructure free to move at its ends causes a free thermally induced axial strain, $\varepsilon_{f}^{t h}$, as

$$
\varepsilon_{f}^{t h}=-\alpha \Delta T_{a}
$$

where $\alpha$ is the linear thermal expansion coefficient of the material. A linear distribution of temperature variation applied to an energy geostructure free to move at its ends 
causes the development of a free thermally induced curvature, $\chi_{f}^{\text {th }}$, as

$$
\chi_{f}^{t h}=-\frac{\alpha}{I} \int_{A^{*}} y_{h} \frac{2 \Delta T_{c}}{h} d A^{*}=-\frac{2 \alpha \Delta T_{c}}{h}
$$

where $I$ is the moment of inertia of the cross-section $A^{*}$, and $y_{h}$ is the coordinate along the structure height $h$.

A partial restraint applied to an energy geostructure by any given boundary condition yields an observed axial deformation and curvature that are a fraction of the ones under free thermal deformation conditions. The partial restraint of axial deformation and curvature leads to blocked contributions of the same variables.

The preceding considerations yield the definition of a degree of freedom associated with axial effects [10]

$$
D O F_{a}=\frac{\varepsilon_{o}^{t h}}{\varepsilon_{f}^{t h}}
$$

and a degree of freedom associated with flexural effects [66]

$$
D O F_{c}=\frac{\chi_{o}^{t h}}{\chi_{f}^{t h}}
$$

where $\varepsilon_{o}^{t h}$ and $\chi_{o}^{t h}$ are the observed thermally induced axial strain and curvature, respectively. Internal actions develop as a consequence of the blocked portion of deformations. The restraint of a constant distribution of temperature variation causes a thermally induced axial force. The restriction of linear distribution of temperature variation causes a thermally induced bending moment. The observed thermally induced axial force, $N_{o}^{t h}$, and bending moment, $M_{o}^{\text {th }}$, caused by such temperature variations can be quantified as

$$
\begin{aligned}
& N_{o}^{t h}=A E \alpha \Delta T_{a}\left(1-D O F_{a}\right) \leq N_{b}^{t h} \\
& M_{\mathrm{o}}^{t h}=E I \frac{2 \alpha \Delta T_{c}}{h}\left(1-D O F_{c}\right) \leq M_{b}^{t h}
\end{aligned}
$$

where $N_{b}^{t h}$ and $M_{b}^{t h}$ are the axial force and bending moment under completely blocked deformation conditions, respectively.

Equations (6)-(11) can estimate the thermally induced variations of axial forces and bending moments in relevant energy geostructures via the consideration of their material properties. The values of the degree of freedom to be used in these expressions may be assumed as equal to those available in the literature for comparable structural restraints, as well as energy geostructure geometries and material properties. Typical values of $D O F_{a}$ are reported elsewhere [5].

The previous approaches idealize the behavior of the reinforced concrete as linear thermo-elastic in both compression and traction. Advanced analysis of the actual thermally induced stress that develops when the tensile strength of concrete may be exceeded (thus involving behavior that is no more linear thermo-elastic) has been recently presented for energy piles [67]. This theoretical approach may be relevant to perform relatively advanced structural analyses of energy piles, especially when dealing with cooling thermal loads applied to such foundations. These loads can potentially cause cracks in the concrete, which need to be limited $[34,35]$.

\subsubsection{Load-transfer models}

Load-transfer models fundamentally draw from the works of Winkler [68] to describe the load-displacement behavior of conventional walls and slabs, and Coyle and Reese [69] to describe the load-displacement behavior of conventional piles. In recent years, these models have been extended to describe single energy piles [59,70-74], energy pile groups [75], as well as energy walls, slabs and cut-and-cover tunnels [66] subjected to both mechanical and thermal loads.

Load-transfer models solve the actual equilibrium of energy geostructures. In this approach, any modeled geostructure is discretized in several elements. These elements interact with the ground via springs that obey a given constitutive law (e.g., theoretically or experimentally determined).

Load-transfer models can thus more adequately account for the influence of both mechanical and thermal loads compared to approaches resorting to charts. These models also have the advantage of being handy in application [58]. However, load-transfer models are inferior to continuum analysis models in that they do not account for the interaction between soil elements in a continuum way and do not reproduce soil behavior beyond its interface with the geostructure [76,1].

\subsection{Geotechnical aspects}

\subsubsection{Available investigation methods}

The analytical investigation of geotechnical aspects characterizing energy geostructures can be achieved through the use of:
1) Displacement charts;
2) Interaction factor charts;
3) Continuum analysis models;
4) Load-transfer models;

Displacement charts serve category $2 \mathrm{~A}$ analysis and design approaches. Interaction factor charts serve category 2B approaches. Continuum analysis models serve category $3 \mathrm{~A}$ approaches. Load-transfer models can be considered to serve category $3 \mathrm{~A}$ or even $3 \mathrm{~B}$ approaches. These methods include those described in the previous sections for addressing structural aspects, in addition to others primarily focusing on groups of energy piles and barrettes.

\subsubsection{Displacement charts}

Various charts provide estimations of the vertical head displacements that are likely to characterize cylindrical energy piles due to thermal loads [e.g., 57-61,77,78] and mechanical loads [e.g., 62-65]. Similar to the stress charts, the displacement charts are typically based on the 
results of load-transfer investigations or finite element simulations.

Examples of charts providing the vertical head displacement of a single cylindrical energy pile subjected to mechanical and thermal loading in an elastic soil mass are reported in Fig. 7 and Fig. 8, respectively. The provided values of displacement are expressed per unit of mechanical or thermal loading applied. The thermally induced displacement is reported in absolute value to be representative of both heating and cooling thermal loads that involve reversible conditions for the soil [77-79].

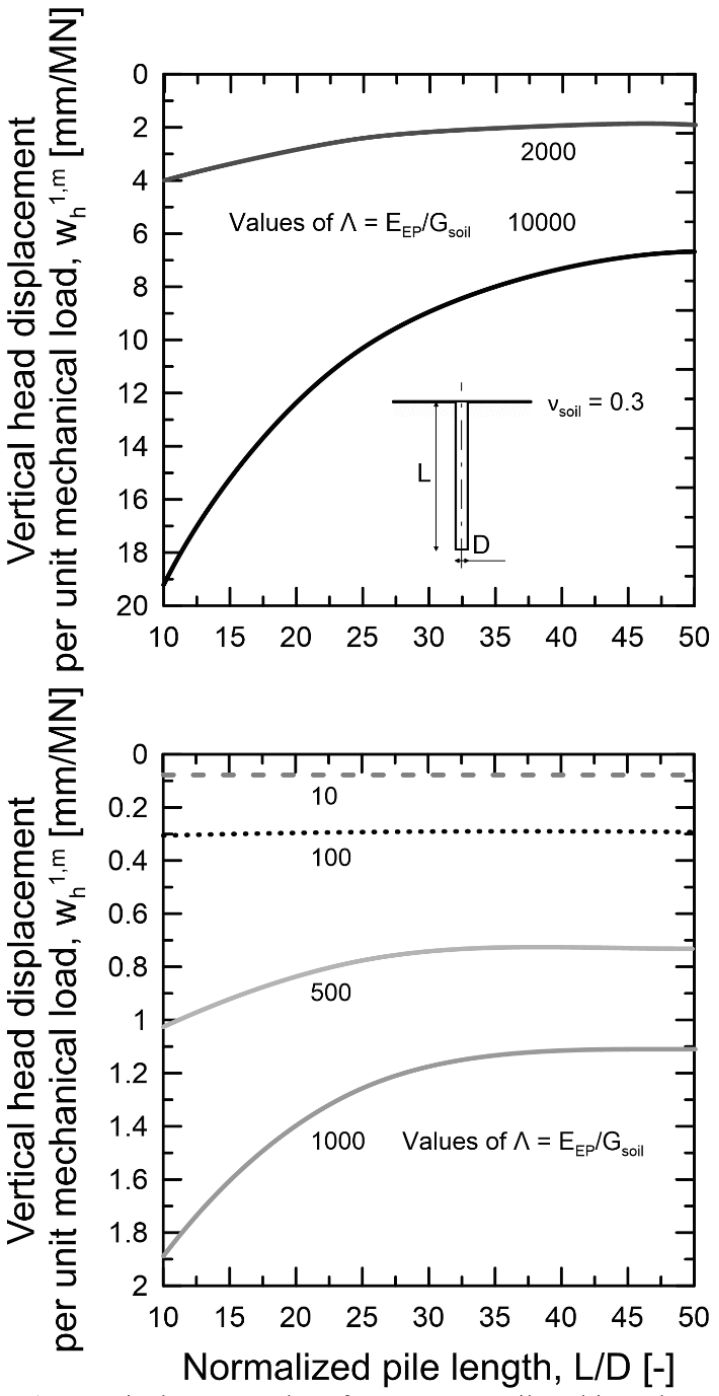

Fig. 7: Displacement chart for an energy pile subjected to mechanical loading (modified after Laloui and Rotta Loria [1]).

$\boldsymbol{\Lambda}=\boldsymbol{E}_{\boldsymbol{E} \boldsymbol{P}} / \boldsymbol{G}_{\text {soil }}$ is the pile-soil stiffness ratio, with $\boldsymbol{E}_{\boldsymbol{E} \boldsymbol{P}}$ the Young's modulus of the pile and $\boldsymbol{G}_{\text {soil }}$ the shear modulus of the soil, and $\boldsymbol{v}_{\text {soil }}$ is the Poisson's ratio of the soil.

The available displacement charts may be applied in an approximate manner to the analysis and design of energy piles as well as energy barrettes that do not have a cylindrical shape by considering an equivalent diameter. This equivalent diameter reads

$$
D_{b}=\frac{2}{\sqrt{\pi}} \sqrt{B W}
$$

where $D_{b}$ is the equivalent diameter of a cylindrical pile representing a barrette characterized by a rectangular cross-sectional area of breadth $B$ and width $W$.

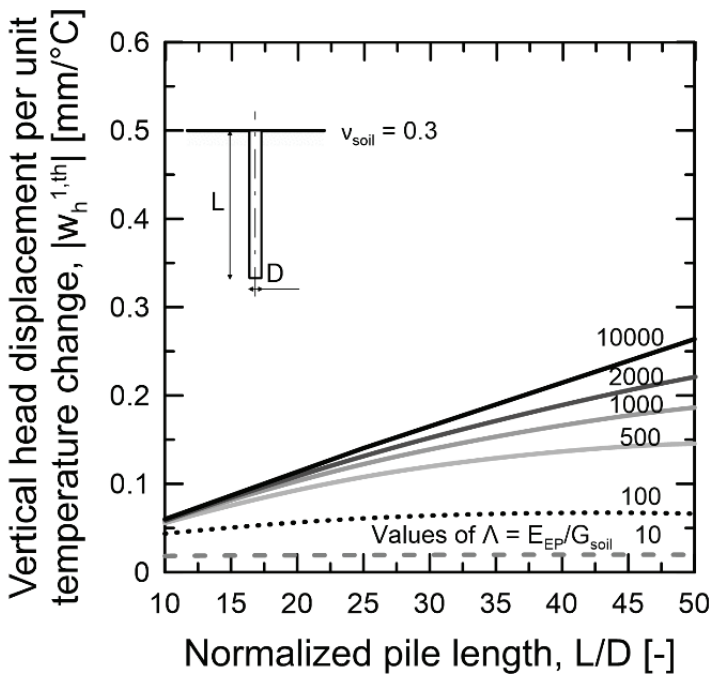

Fig. 8: Displacement chart for an energy pile subjected to thermal loading (modified after Rotta Loria and Laloui [77]).

\subsubsection{Interaction factor charts}

Charts that quantify the degree of mechanical interaction between energy piles located sufficiently close to each other and subjected to mechanical and thermal loads are available for situations in which no slab is present at the head of the piles $[62,80,77,78]$, or a slab is connecting the piles $[81,82,60]$. Such a degree of interaction is quantified through a so-called displacement interaction factor, which quantifies the effects caused by loading a source pile on a receiver pile in a pair [83]. Displacement interaction factors are provided in charts for uniform soil masses, as well as for situations involving the presence of a finitely or infinitely rigid bearing stratum.

The interaction factor can be defined as [77]

$$
\Omega=\frac{w_{j}}{w_{i}}
$$

In defining the interaction factor, $w_{j}$ is the vertical head displacement of a receiver pile in a pair, whereas $w_{i}$ is the vertical head displacement of a single isolated pile subjected to the same load applied to the source pile in the pair. This definition of $\Omega$ links the effect of loading a source pile on a receiver pile in a pair with the response of the source pile in an isolated case [77].

Examples of displacement interaction factor charts for energy piles subjected to mechanical and thermal loading are presented in Fig. 9 and Fig. 10, respectively. Application of the interaction factor method via the use of charts allows estimating the vertical displacement characterizing energy pile groups in most of the conditions that are likely to be encountered in practice. This goal can be achieved as follows $[77,83]$ : 


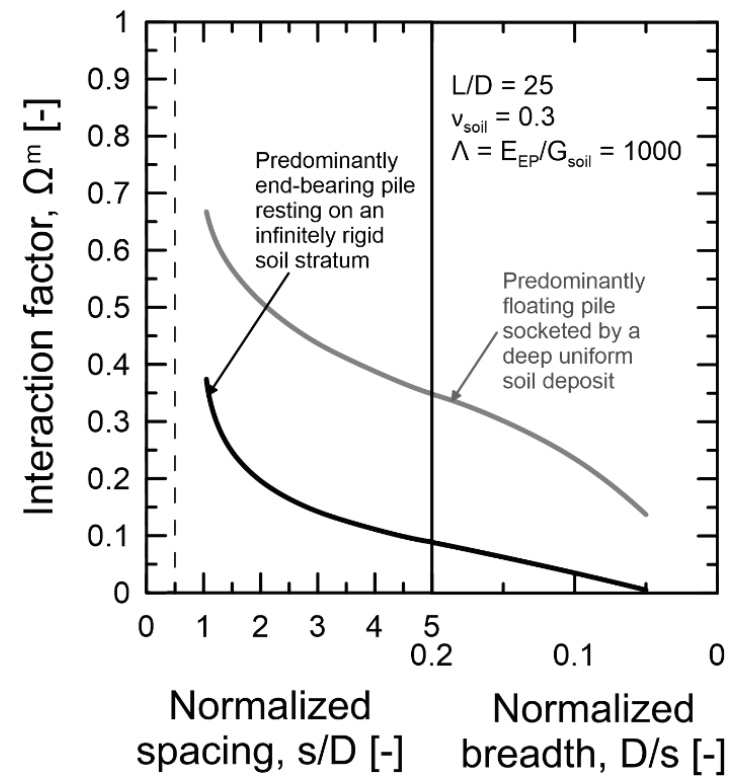

Fig. 9: Interaction factor for energy piles subjected to mechanical loading (chart drawing from the works of Poulos and Davis [62], and Poulos and Mattes [80]; interaction factors calculated according to Rotta Loria and Laloui $[77,78])$.

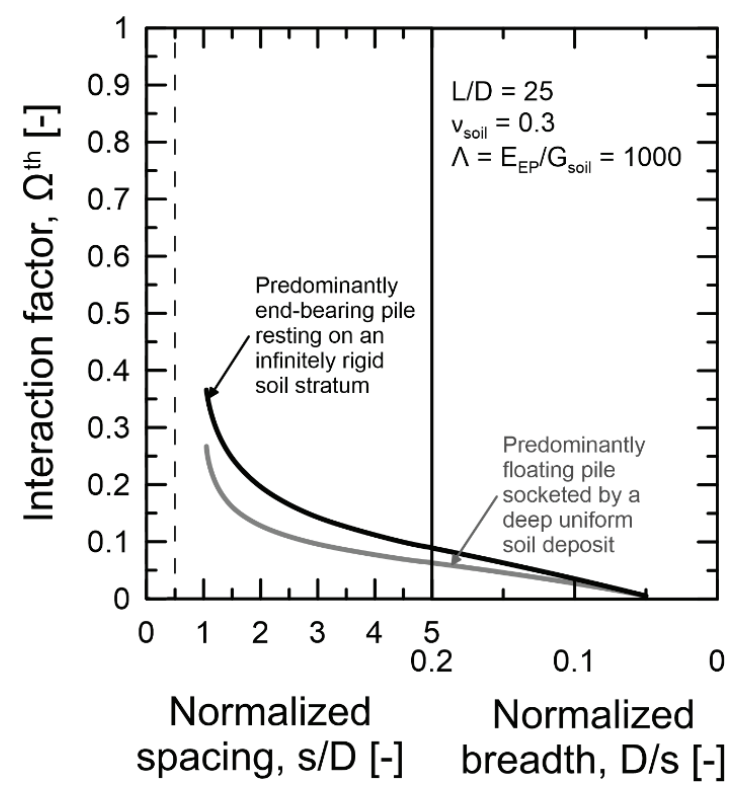

Fig. 10: Interaction factor for energy piles subjected to thermal loading (interaction factors calculated according to Rotta Loria and Laloui $[77,78])$.

1. Analysis of a single isolated energy pile subjected to a mechanical or a thermal load to define the pile vertical head displacements per unit of such loads, $w_{h}^{1, m}$ and $w_{h}^{1, t h}$, respectively. This step can be accomplished by referring to Fig. 7 and Fig. 8.

2. Definition of $\Omega$ for a pair of two piles at any given center-to-center distance, i.e., spacing. This step can be accomplished by referring to Fig. 9 and Fig. 10 .

3. Analytical analysis of the displacement behavior of the pile group, which is suggested for $s / D \geq 5$ $[77,78]$. This analysis allows determining the vertical head displacement $w_{k}$ of any pile, $k$, composing a general pile group with a total number of piles, $n_{E P}$, in which some or all of the piles may be subjected to mechanical and/or thermal loading, supposing the superposition principle to be valid.

In the case of piles subjected to mechanical loads, the interaction factor analysis can be performed as

$$
w_{k}=w_{h}^{1, m} \sum_{i=1}^{i=n_{E P}} P_{i} \Omega_{i k}^{m}
$$

where $P_{i}$ is the applied mechanical load to the head of pile $i$, and $\Omega_{i k}^{m}$ is the interaction factor referring to the head of two piles subjected to mechanical loading in a pair corresponding to the spacing between piles $i$ and $k$. In the case of piles subjected to thermal loads, this analysis can be performed as

$$
w_{k}=w_{h}^{1, t h} \sum_{i=1}^{i=n_{E P}} \Delta T_{i} \Omega_{i k}^{t h}
$$

where $\Delta T_{i}$ is the applied temperature variation to pile $k$, and $\Omega_{i k}^{t h}$ is the interaction factor referring to the head of two piles subjected to thermal loading in a pair corresponding to the spacing between piles $i$ and $k$.

\subsubsection{Continuum analysis models}

Continuum analysis models to address geotechnical aspects of energy geostructures are currently available for energy pile groups. Specifically, the equations of Mindlin [84] have been used to develop an interaction factor analysis method for energy pile groups subjected to mechanical and thermal loads [79]. This analysis approach modifies and extends to energy piles previous solutions for conventional piles subjected to only mechanical loads [85]. The main advantage of using this approach compared to charts is that it defines interaction factors with depth and not only for the head of energy piles. An extension of this approach that accounts for nonlinear soil deformation [86], which draws from previous contributions for conventional piles [87], is also available.

No continuum analysis models appear to be available for other energy geostructures than energy piles subjected to mechanical and thermal loads.

\subsubsection{Load-transfer models}

The available load-transfer models to address geotechnical aspects of energy geostructures include formulations for single energy piles [59,70-74], energy pile groups $[86,79,75,88]$, as well as energy walls, slabs and cut-and-cover tunnels [66]. For about two decades, in contrast to the widely established closed-form solutions allowing to describe the vertical displacements of single piles subjected to mechanical loads [89,90], no closedform solutions have been available for single energy piles subjected to thermal loads. A contribution by Iodice et al. [74] has filled this long-lasting scientific and engineering gap. Not only the proposed closed-form solution allows a handy analysis of single energy piles subjected to mechanical and thermal loads [74]. It can also address energy pile groups when applied in combination with the 
interaction factor method $[86,79]$, the equivalent pier method [88] or the modified load-transfer method [75].

While load-transfer models can be applied in combination with continuum models (e.g., the equations of Mindlin [84]) to directly address the mechanically and thermally induced interactions characterizing pile groups $[91,79]$, this approach often leads to unsatisfactory predictions [79]. A valuable approach to overcome the limitation above is to indirectly address the mechanically and thermally induced interactions between pile groups through the modification of the load-transfer relationship of a single pile [92-94,75]. Highly adherent predictions of experimental observations can be achieved through this approach [75] and effectively serve the analysis of geotechnical and structural aspects.

\subsection{Summary}

An extensive number of analytical models and methods are available to address a variety of energy, structural and geotechnical aspects involved with the combined energy transfer and structural support roles of energy geostructures. While a greater number of theoretical methods are available to describe single and groups of energy piles, theoretical advances are increasing for other types of energy geostructures as well.

\section{Numerical frameworks}

\subsection{General}

This section presents a summary of selected theoretical methods serving the numerical analysis and design of energy geostructures. This summary does not focus on the extensive available numerical studies investigating energy geostructures, which have been discussed elsewhere $[1,5,9]$. Instead, the following summary is centered on numerical strategies (resorting to the finite element method and included in category 3 approaches) to account for critical features of the heat transfer, mass transfer and deformation phenomena involved with energy geostructures.

\subsection{Energy aspects}

\subsubsection{Simulation of the geothermal operation}

An approximate modeling approach of the geothermal operation of energy geostructures consists of imposing temperature variations or thermal powers on such geostructures. This approach has been employed in various numerical investigations of energy piles [e.g., 14,95-99], as well as in simulations developing stress and displacement charts [e.g., 58,77,78]. It can be considered valuable to address structural and geotechnical aspects because it reproduces more uniform temperature variations than those that can be expected in practice [100], consequently leading to greater thermally induced strains and stresses. Nevertheless, by neglecting the actual presence of the pipes within energy geostructures, it noteworthy simplifies the investigation of energy aspects.
The advent of relatively sophisticated and accessible numerical software currently facilitates the modeling of the pipes embedded in energy geostructures that significantly characterize their geothermal operation and the associated heat and mass transfers. Through this capability, pipes can be modeled as linear elements [e.g., $101-104,39,105,106,37,107-109,38]$ or heat sources [e.g., 110,12,100], but also as actual three-dimensional ducts [e.g., 54]. The hypotheses involved in the previous approaches can lead to predictions that may be more or less adherent to the actual thermo-hydraulic conditions occurring within the pipes. Meanwhile, the modeling of the pipes embedded within energy geostructures is essential for numerical simulations aiming to reproduce their geothermal operation comprehensively.

\subsubsection{Modeling of environmental boundary conditions}

The modeling of the ground surface can account for different environmental conditions. These conditions are generally represented through adiabatic or prescribed temperature boundary conditions (e.g., constant or varying in time). Adiabatic conditions aim to reproduce highly thermally insulated buildings. Prescribed temperature conditions are employed to reproduce surface environments that interact through their temperature field with the subsurface. Investigations highlight that the ground surface thermal boundary conditions can significantly influence both the heat and mass transfer phenomena [111] as well as the deformation [112] characterizing energy piles.

Adequate thermal boundary conditions should then be employed to realistically address the interaction between energy geostructures and underground built environments (e.g., when the airflows in such environments are not modeled). Energy geostructures characterized by an interface with underground built environments allow the harvesting of both geothermal and aerothermal energy [109]. Meanwhile, 'hot' and 'cold' tunnels can aid or harm energy operations depending on the targeted application [e.g., 113,114]. Therefore, heat transfer with only the ground or also with the underground built environments may be relevant to achieve and simulate. Typical boundary conditions for the interface(s) between energy geostructures and underground built environments include adiabatic [e.g., 115], prescribed temperature [e.g., $106,116-120]$, or convection boundary conditions [e.g., $109,38,40]$. The immediate presence of such conditions on the boundary of energy geostructures can involve completely different energy, geotechnical and structural performances. As a result, these boundary conditions critically influence the analysis and design of energy geostructures. A comprehensive analysis of this topic for energy walls is reported elsewhere [121]. Adiabatic, prescribed temperature and convection boundary conditions can be mathematically expressed as

$$
\begin{aligned}
& -n_{i} \cdot(-\lambda \nabla T)=0 \\
& T_{\infty}=T_{0} \\
& \dot{q}_{i}=h_{c}\left(T_{\infty}-T\right)
\end{aligned}
$$


where $n_{i}$ is the outward pointing normal vector from the relevant boundary, $\lambda$ is the thermal conductivity of the relevant material, $T$ is the temperature and $T_{\infty}$ is the temperature of the far-field. Typically, $T_{\infty}$ is considered to coincide with the relevant air temperature $T_{a}$. In general [1]: equation (16) is employed to prescribe no heat flux across a boundary and involves considering ideal thermal insulation on the selected boundary; equation (17) is employed for boundaries that are considered to be at a given temperature; equation (18) is employed to reproduce the heat transfer linked with a non-isothermal flow over a boundary without the need of explicitly modeling it via computational fluid dynamics tools.

Simulating the actual dynamics of airflows characterizing underground built environments adjacent to energy geostructures is indeed feasible [e.g., 108,13]. This approach is needed to capture the development and the perturbations of the thermal and boundary layers that govern the heat transfer between energy geostructures and the embedded built environments [13]. Nevertheless, this endeavor is markedly time-consuming when dealing with fully turbulent airflow conditions, so it is only suggested for advanced investigations (category $3 \mathrm{C}$ approaches).

(a)
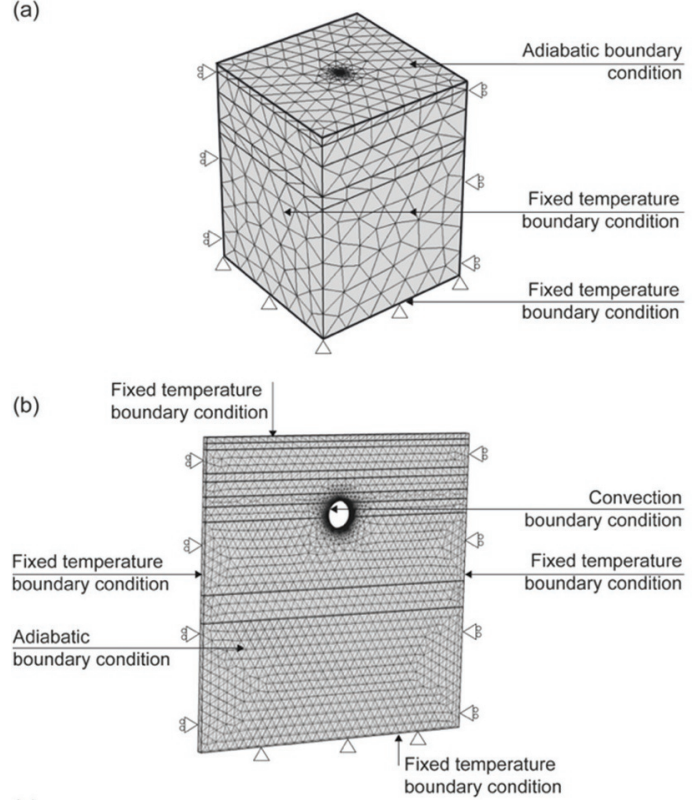

(c)

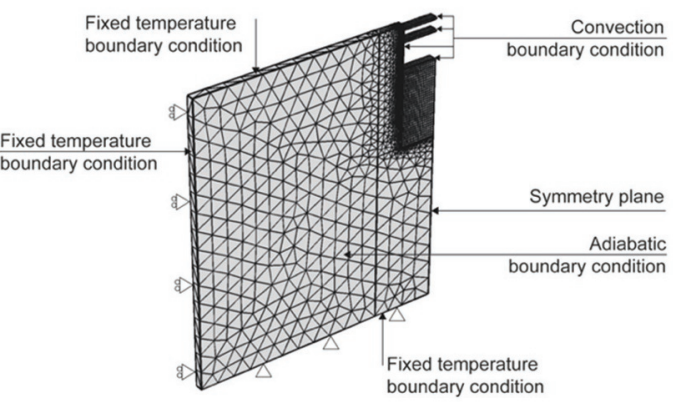

Fig. 11: Examples of thermal boundary conditions applied to numerical models of (a) energy piles (modified after Batini et al. [101]), (b) energy tunnels (modified after Cousin et al. [109]) and (c) energy walls (modified after Zannin et al. [38]).

\subsubsection{Assessment of energy performance}

Time-dependent numerical simulations are necessary to assess the energy performance of energy geostructures comprehensively. The reason for this is that applied thermal loads are never constant with time in energy systems [5].

In principle, numerical simulations allow modeling the response of energy systems for any time scale. In practice, many numerical simulations addressing the geothermal operation of energy geostructures employ simplified thermal loading paths.

Simplified thermal loading paths usually involve some form of load aggregation over time, or constant loads over time [122]. Such load aggregations may involve simplified time-varying thermal loads for given time scales (e.g., from the daily to the monthly or seasonal time scales, up to the yearly time scale), or constant thermal loads over time scales of up to the monthly scale [1]. In this latter condition, a traditional approach is to run simulations until steady thermal conditions are reached by considering constant values of inlet temperature and flow velocity of the heat carrier fluid circulating in the pipes of energy geostructures [e.g., 101,39]. In this way, through 'short-term' simulations, the lower bounds of thermal power and energy that are likely to be expected in practice can be quantified. The rationale for this approach is that, according to Duhamel's theorem, the dynamic energy operation of energy geostructures can be reproduced by the superposition of numerous, steady responses.

\subsection{Structural aspects}

\subsubsection{Modeling of applied loads}

The influence of mechanical loads is typically reproduced via numerical simulations through the application of imposed forces or displacements. As anticipated, thermal loads can be reproduced through the use of prescribed thermal powers, prescribed temperature evolutions, or the modeling of the pipes embedded in such geostructures.

\subsubsection{Modeling of structural restraints}

The most appropriate approach to reproduce structural restraints, such as a slab resting on the ground that connects energy piles in a group, is to model the considered structural elements. An alternative approach is to quantify the stiffness associated with the modeled restraint and use closed-form expressions available for such purpose [e.g., 123], which can still yield theoretical predictions representative of reality [e.g., 124,75]. Endrestraint conditions markedly characterize the significance of thermally induced stresses, strains and displacements in energy geostructures [125]. Variations in end-restraint conditions notably cause changes in the location of the null point (also called neutral plane) [97], i.e., the setting along with energy piles, barrettes and walls where zero thermally induced vertical displacements occur. Deeper locations of the null point cause more significant vertical head displacements due to heating or cooling thermal loads. These vertical head displacements, in turn, can lead to unwanted effects for the structural performance of the considered energy geostructures. 


\subsubsection{Modeling of reinforced concrete behavior}

The behavior of the reinforced concrete that constitutes energy geostructures is generally assumed as linear thermo-elastic. Nevertheless, consideration of the actual limited tensile strength $[35,67]$ and thermally induced creep [126] of reinforced concrete can be noteworthy to develop advanced analysis and design considerations (category $3 \mathrm{C}$ approaches).

\subsubsection{Reduction of problem dimensions}

Three-dimensional problems involving energy geostructures can be reduced to two-dimensional ones for the sake of limiting computational efforts associated with numerical simulations. In this context, out of plane effects due to heat transfer, mass transfer and deformation phenomena are not considered. Although such approximation may be regarded as noteworthy [127], mathematical formulations allowing to correct the results of these numerical investigations have been presented for both energy piles [128] and energy walls [129].

\subsection{Geotechnical aspects}

\subsubsection{Modeling of the interface between energy} geostructures and the ground

The construction of energy geostructures involves a significant modification of the ground properties for regions that can extend from a few millimeters to centimeters from the edge(s) of such geostructures. This fact leads to the formation of an interface of varying thickness between energy geostructures and the ground.

Modeling a disturbed region of the ground around energy geostructures may be relevant to thoroughly simulate the actual heat and mass transfers occurring therein [40]. Modeling an interface with properties that differ from those of the ground is critical to address nonlinear deformation phenomena due to significant loads applied to energy geostructures, which would be poorly predicted otherwise [130]. This endeavor does not appear essential for loading levels characteristic of serviceability conditions. In those cases, the selection of representative deformation moduli for the ground can effectively address the deformation of energy geostructures without the consideration of different properties for an interface. This consideration is supported by evidence developed for conventional geostructures [e.g., 76,131,132]. Yet, it is validated via the comparison between numerical, analytical and experimental results [e.g., 18,86,22].

\subsubsection{Modeling of soil and rock behavior}

The behavior of the ground that surrounds energy geostructures can be simulated via constitutive models of varying complexity. These models include: linear elastic models [e.g., 77,78]; linear thermo-elastic models [e.g., $18,133,134,22]$; linear thermo-elastic, perfectly plastic or plastic hardening models [e.g., $14,110,97,98,135,136,99,103,118,106,137,138]$; and linear or non-linear thermo-elastic, thermo-plastic models resorting to the theories of critical state or bounding surface plasticity [e.g., 95,139,140].
The use of elastic models is only suggested when the thermal expansion coefficient of the ground is lower than the reinforced concrete, the ground is overconsolidated and simplified analyses are targeted. The use of linear thermo-elastic models is suggested for analyses that address serviceability conditions. Consideration of linear thermo-elastic, perfectly plastic or plastic hardening models allows capturing the irreversible effects caused by significant loading levels, which might trigger cumulative stresses or displacements variations in energy geostructures over the successive thermal cycles applied. Consideration of linear or non-linear thermo-elastic, thermo-plastic models resorting to the theories of critical state or bounding surface plasticity can address some of the most advanced aspects of soil behavior, such as the phenomenon of heating induced contraction [e.g., $25,26,32,141]$, and may be required for highly advanced analyses and designs (category $3 \mathrm{C}$ approaches).

\subsubsection{Modeling of ground properties}

The inclusion of appropriate ground properties in numerical simulations (and, when applicable, analytical simulations) is paramount to realistically describe the heat transfer, mass transfer and deformation phenomena that characterize energy geostructures. When considering deformation phenomena, adequate choice of the thermal expansion coefficient of the ground has been proven crucial to realistically estimate the thermally induced deformations that characterize energy geostructures (e.g., especially at successive stages of geothermal operations) [e.g., 142,143,18,22]. Soils characterized by a more significant thermal expansion coefficient than the energy geostructures can cause tensile stresses in such geostructures for significant soil volumes that are affected by temperature variations. These tensile stresses would never be predicted if unsuitable values of the thermal expansion coefficient (e.g., higher than that of energy geostructures) would be considered [22]. Adequate estimation of the thermal expansion coefficient of the ground is thus an aspect of comparable importance to the consideration of appropriate values of deformation moduli and shear strength properties highlighted for conventional geostructures [e.g., 76].

\subsubsection{Modeling of cyclic degradation effects}

Accumulation of vertical displacements caused by the combined influence of mechanical loads and cyclic thermal loads can characterize energy geostructures. Such a phenomenon is due to degradation effects at the interface between energy geostructures and the ground.

Prediction of cyclic degradation effects requires adequate constitutive models [e.g., 72,95,136,144,139,145,140,137]. Consideration of these effects may be noteworthy when dealing with energy geostructures embedded in soft ground or subjected to significant loading levels (e.g., exceeding half of the load capacity of the geostructure). Otherwise, such effects may be considered limited, if present, and attenuated by the restraint of structural elements connected to most energy geostructures (e.g., a slab for energy piles, barrettes and walls) [1]. 


\subsection{Summary}

The numerical simulation of energy geostructures represents the most advanced approach that can serve analysis and design purposes. Any complete analysis or design of energy geostructures should include numerical simulations of energy, structural and geotechnical aspects.

\section{Theoretical predictions of observations}

\subsection{General}

This section expands on a comparison between analytical and numerical predictions of experimental observations referring to a full-scale energy geostructure. The aim of this comparison is to highlight how adequate analytical and numerical models can both capture experimental observations comparably well if applied with suitable hypotheses and judgment. This statement appears to hold for general predictions of heat transfers, mass transfers and deformations involved with energy geostructures.

The focus is restrained hereafter to the analysis of the vertical deformation of energy piles. As an example of the application of theory to practice, the result of 'Class C1' analytical and numerical predictions [146] are presented.

\subsection{Case study}

The considered case study is an energy pile group constructed at the Swiss Federal Institute of Technology in Lausanne (EPFL). For this facility, Mimouni and Laloui [17] and Rotta Loria and Laloui [18,22] reported the results of a series of full-scale field tests involving energy piles subjected to thermal and mechanical loading.

The facility consist in four energy piles made of reinforced concrete characterized by a diameter of $D=$ $900 \mathrm{~mm}$ and a length of $L=28 \mathrm{~m}$, and bored in a stratified soil deposit. An additional sixteen conventional piles characterize the considered facility. The soil deposit embedding the piles is overconsolidated and fully saturated with water due to the presence of the groundwater table at the ground surface. It includes a shallow alluvial soil layer from the surface (coinciding with the level of the successively built $0.9 \mathrm{~m}$ thick slab) to a depth of $z=8.6 \mathrm{~m}$. Below the alluvial soil layer, a sandy-gravelly moraine layer reaches a depth of $z=16.6$ $\mathrm{m}$. A layer of bottom moraine is present below the sandygravelly moraine layer, down to a depth of $z=20.1 \mathrm{~m}$. A molasse layer extends at greater depths below the bottom moraine. A $0.9 \mathrm{~m}$ thick reinforced concrete slab, with dimensions of $L_{\text {slab }}=26 \mathrm{~m}$ and $B_{\text {slab }}=10 \mathrm{~m}$ and resting on the ground, connect all the energy and conventional piles. A sketch of the site is shown in Fig. 12.

\subsection{Prediction features}

The following predictions refer to two series of experiments carried out by Rotta Loria and Laloui $[18,22]$, which are labeled in the following as Test 20EP1 and Test 20EPall. In Test 20EP1 [18], thermal loading was applied to the central energy pile only (EP1), and its deformation was monitored with that of the neighboring energy piles (EP2, EP3 and EP4). The focus will be given hereafter to the deformation of EP1. In Test 20EPall [22], thermal loading was applied to all the energy piles (EP1EP4), and their deformation was monitored over time.

The predictions of Test 20EP1 and Test 20EPall reported hereafter resort to load-transfer models [124] and finite element models $[18,22]$. The first set of proposed predictions addresses the energy pile EP1 subjected to thermal loading in Test 20EP1. This is done through a relatively simple load-transfer model of an energy pile assumed to be isolated, while through a more complex three-dimensional finite element model that reproduces an energy pile in the actual group that characterizes the case study. The second set of predictions described hereafter addresses the average response of energy piles EP1, EP2, EP3 and EP4 subjected to thermal loading in Test 20EPall. This is done through a load-transfer model reproducing a single equivalent pier, and a threedimensional finite element model of the energy pile group that characterizes the case study.

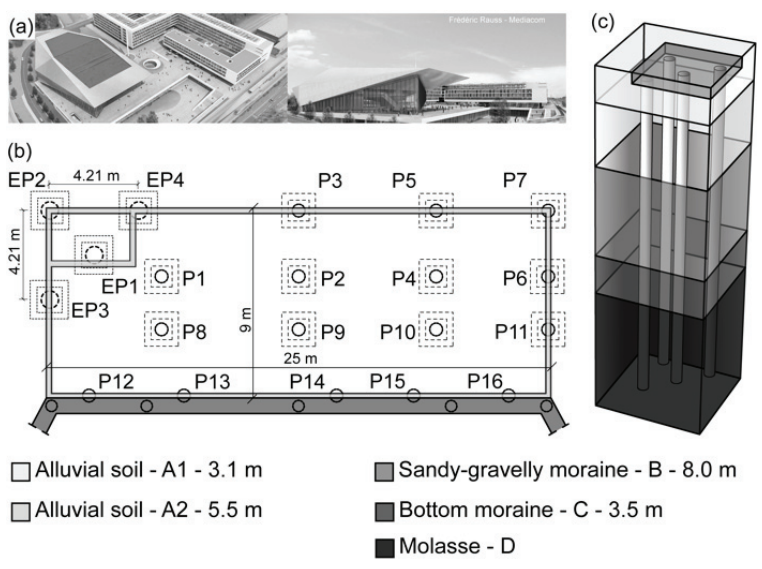

Fig. 12: Site features (modified after Rotta Loria and Laloui [18]).

\subsection{Vertical deformation of single energy piles}

Fig. 13 shows the measured and computed evolutions of the degree of freedom, $D O F_{a}=\varepsilon_{o}^{t h} / \varepsilon_{f}^{t h}$, along the normalized depth, $z^{*} / L$, of a single thermally loaded energy pile in a group. The degree of freedom represents a proxy of the vertical deformation of the energy pile, including information about restraint effects. Results are plotted for average temperature variations along the length of the energy pile of $\overline{\Delta T}=5,10,15$ and $20^{\circ} \mathrm{C}$.

The predictions achieved with the load-transfer model closely capture the observations for applied temperature variations of $\overline{\Delta T}=5$ and $10^{\circ} \mathrm{C}$, which correspond to the early stages of the geothermal operation of energy pile EP1. An increasing difference between the predictions and the observations in correspondence with the shallower portion of the energy pile is observed for temperature variations of $\overline{\Delta T}=15$ and $20^{\circ} \mathrm{C}$, which correspond to successive stages of the geothermal operation of energy pile EP1. This difference is attributed 
to the fact that the load-transfer model of energy pile EP1 does not account for the mechanical interactions with the neighboring energy piles EP2, EP3 and EP4 that are progressively caused in practice by their indirect heating.

The predictions achieved with the finite element model thoroughly capture the observations, irrespective of the considered stage of the geothermal operation. This result is mainly due to the capability of the threedimensional finite element model to account for the impact of temperature variations associated with the thermal loading of energy pile EP1 on the thermally induced deformation of the surrounding ground and the neighboring energy piles EP2, EP3 and EP4.

Despite some differences, the analytical and numerical predictions may both be considered adequate to serve practical purposes. Consideration of more advanced aspects of the problem, such as the temperature sensitivity of the soil by the load-transfer model, may lead to closer predictions of observations. A comprehensive discussion on this subject is treated elsewhere $[75,124]$.

\subsection{Vertical deformation of energy pile groups}

Fig. 14 shows the measured and computed evolutions of the degree of freedom, $D O F_{a}=\varepsilon_{o}^{t h} / \varepsilon_{f}^{t h}$, along the normalized depth, $z^{*} / L$, of a thermally loaded energy pile group. Results are plotted for average temperature variations applied along the length of the four energy piles of $\overline{\overline{\Delta T}}=5,10,15$ and $20^{\circ} \mathrm{C}$.

The predictions obtained with the load-transfer model capture well the observations for applied temperature variations of $\overline{\overline{\Delta T}}=5$ and $10^{\circ} \mathrm{C}$, which correspond to the early stages of the geothermal operation of energy piles EP1-EP4. These predictions are still satisfactory in correspondence of the shallower soil layers for applied temperature variations of $\overline{\overline{\Delta T}}=15$ and $20{ }^{\circ} \mathrm{C}$, which correspond to later stages of the geothermal operation. In contrast, relatively poor predictions are obtained at these stages in correspondence of the bottom molasse layer. This result is due to the more pronounced thermally induced deformation of the molasse layer than the energy piles, which prominently develops at successive stages of the geothermal operation because of a marked volume of soil that is subjected to temperature variations [18]. This result is not captured by the predictions obtained with the load-transfer model because they consider a thermal expansion coefficient of the equivalent pier equal to that of the piles and an isothermal soil.

The predictions achieved with the finite element model thoroughly capture the observations, irrespective of the considered stage of geothermal operation. These predictions are particularly capable of capturing well the observations at successive stages of the geothermal operation because they account for the three-dimensional geometry of the case study, the temperature sensitivity of the ground, and the modeling of the actual heat transfer.

Despite the previous different capabilities of the analytical and numerical models, both of the related predictions may be considered valuable for practical investigations.
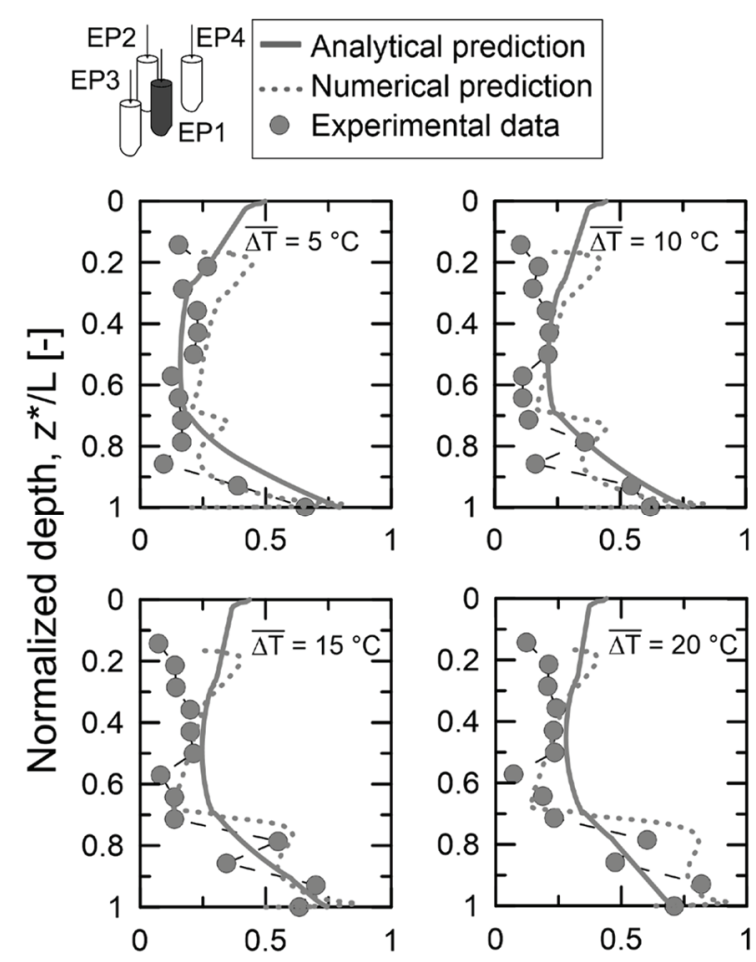

Degree of freedom, $\mathrm{DOF}_{\mathrm{a}}[-]$

Fig. 13: Degree of freedom characterizing a single energy pile at successive stages of geothermal operation $[18,124]$.
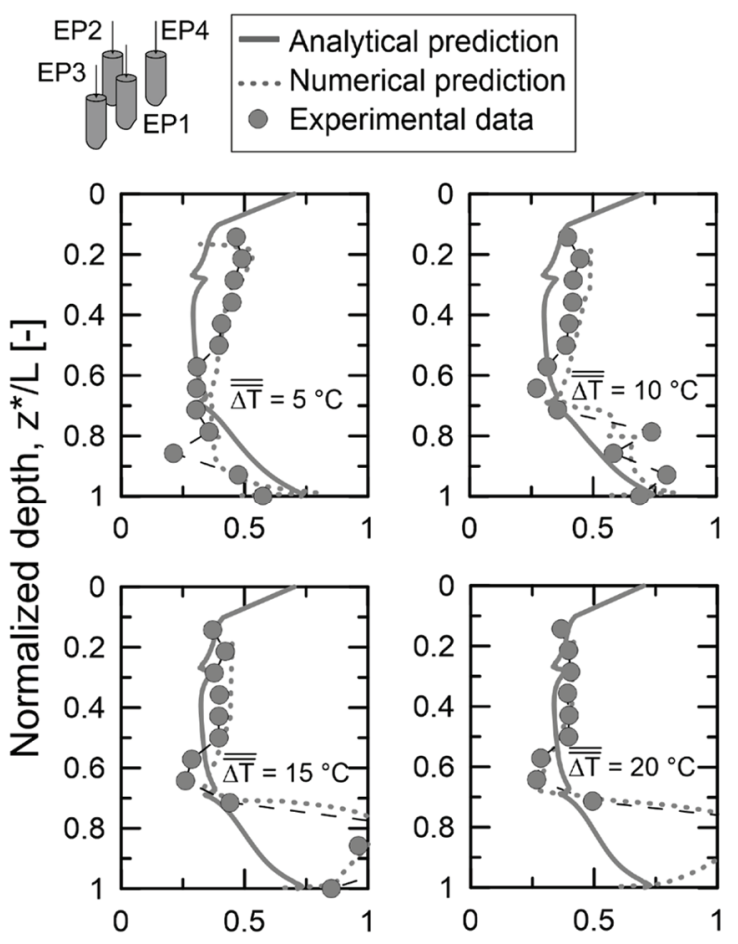

Degree of freedom, $\mathrm{DOF}_{\mathrm{a}}[-]$

Fig. 14: Degree of freedom characterizing energy pile groups at successive stages of geothermal operation $[22,124]$. 


\subsection{Summary}

Analytical and numerical models can capture observations comparably well if resorting to appropriate idealizations and assumptions. The modeling approach should be chosen depending on the specific purpose of the investigation and the level of information that is targeted. In practice, budget considerations may govern such choices. Analytical models may typically be considered suitable for schematic designs while numerical models for detailed designs of energy geostructures.

\section{Closure}

The scientific theory about energy geostructures has advanced dramatically over the past two decades. This work summarized selected theory that can assist the understanding, modeling and prediction of the behavior and performance of energy geostructures (e.g., energy, geotechnical and structural), with a focus on energy piles and barrettes, energy walls and slabs, and energy tunnels.

Scientific theory is essential to address the analysis and design of energy geostructures because it allows solving problems that might only be treated with probable pitfalls through the sole use of experience or best practice methods (if any). It must be borne in mind, however, that scientific theory does represent an idealization of reality. Experimental knowledge and data are thus necessary to validate scientific theory and assist the analysis and design of energy geostructures.

This paper summarizes the content of the Bright Spark Lecture on Energy Geotechnics delivered by the author at the $2^{\text {nd }}$ International Conference on Energy Geotechnics (ICEGT2020), held at the University of California, San Diego, from September 20 to 23,2020 . This work benefits from a multitude of investigations available in the current scientific literature, including various studies developed in collaboration with colleagues and students across the Swiss Federal Institute of Technology in Lausanne and Northwestern University.

The author wishes to greatly acknowledge Professor Lyesse Laloui for sharing invaluable discussions over the years. The author is also grateful to the following collaborators for their contributions in joint studies developed to date: Dr. Alice Di Donna, Margaux Peltier, Benoît Cousin, Jacopo Zannin, Niccolò Batini, Aurélien Vadrot, Matteo Bocco, Cristiano Garbellini and Qazim Llabjani. The author further wishes to thank Dr. Jibril B. Coulibaly for the constructive comments about this paper.

\section{References}

1. L. Laloui and A. F. Rotta Loria, Analysis and Design of Energy Geostructures: Theoretical Essentials and Practical Application (Academic Press, 2019)

2. I. E. A. International Energy Agency, World Energy Statistics and Balances (International Energy Agency, 2019)

3. E. P. B. D. recast, Energy Performance of Buildings Directive, Off. J. Eur. Union 153, 13 (2010)

4. ASHRAE, Vision 2020, 28 (2008)

5. P. Bourne-Webb, S. Burlon, S. Javed, S. Kürten, and F. Loveridge, Renew. Sustain. Energy Rev. 65, 402 (2016)
6. A. Vieira, J. Maranha, P. Christodoulides, M. Alberdi-Pagola, F. Loveridge, F. Nguyen, G. Florides, G. Radioti, F. Cecinato, and I. Prodan, Energies 10, 2044 (2017)

7. J. Fadejev, R. Simson, J. Kurnitski, and F. Haghighat, Energy 122, 390 (2017)

8. P. J. Bourne-Webb and T. M. Bodas Freitas, Renew. Energy 147, 2572 (2020)

9. F. Loveridge, J. S. McCartney, G. A. Narsilio, and M. Sanchez, Geomech. Energy Environ. 22, 100173 (2020)

10. L. Laloui, M. Moreni, and L. Vulliet, Can.

Geotech. J. 40, 388 (2003)

11. H. Brandl, Géotechnique 56, 81 (2006)

12. P. Bourne-Webb, T. B. Freitas, and R. da Costa Gonçalves, Energy Build. 125, 130 (2016)

13. M. Peltier, A. F. Rotta Loria, L. Lepage, E. Garin, and L. Laloui, Appl. Therm. Eng. 159, 113844 (2019)

14. L. Laloui, M. Nuth, and L. Vulliet, Int. J. Numer. Anal. Methods Geomech. 30, 763 (2006)

15. G. A. Akrouch, M. Sánchez, and J.-L. Briaud, Acta Geotech. 9, 399 (2014)

16. J. S. McCartney and K. D. Murphy, DFI J. 6, 26 (2012)

17. T. Mimouni and L. Laloui, Can. Geotech. J. 52, 1913 (2015)

18. A. F. Rotta Loria and L. Laloui, Géotechnique 67, 374 (2017)

19. P. J. Bourne-Webb, B. L. Amatya, K. Soga, T.

Amis, C. Davidson, and P. Payne, Géotechnique 59, 237 (2009)

20. P. J. Bourne-Webb, B. Amatya, and K. Soga, Proc. ICE-Geotech. Eng. 166, 170 (2011)

21. A. F. Rotta Loria and L. Laloui, in Int. Symp.

Energy Geotech. SEG 2018 (2018), pp. 218-225

22. A. F. Rotta Loria and L. Laloui, Géotechnique 68, 834 (2018)

23. R. G. Campanella and J. K. Mitchell, J. Soil Mech. Found. Eng. Div. ASCE 94, 709 (1968)

24. K. R. Demars and R. D. Charles, Can. Geotech. J. 19, 188 (1981)

25. G. Baldi, T. Hueckel, and R. Pellegrini, Can.

Geotech. J. 25, 807 (1988)

26. C. Cekerevac and L. Laloui, Int. J. Numer. Anal. Methods Geomech. 28, 209 (2004)

27. H. M. Abuel-Naga, D. T. Bergado, and B. F. Lim, Soils Found. 47, 423 (2007)

28. A. Di Donna and L. Laloui, Eng. Geol. 190, 65 (2015)

29. A. Vega and J. S. McCartney, Environ. Geotech. 2, 257 (2014)

30. C. W. W. Ng, S. H. Wang, and C. Zhou,

Géotechnique Lett. 6, 124 (2016)

31. J. S. McCartney, Y. Xiao, H. Liu, and H. Liu, Geotech. Test. J. 41, (2018)

32. C. J. R. Coccia and J. S. McCartney, Comput. Geotech. 80, 26 (2016)

33. H. G. Poulos, Géotechnique 39, 365 (1989)

34. A. F. Rotta Loria, DFI J. 12, 94 (2019)

35. A. F. Rotta Loria, M. Bocco, C. Garbellini, A.

Muttoni, and L. Laloui, Geomech. Energy Environ. 21, $100153(2020)$

36. SIA-D0190, Utilisation de La Chaleur Du Sol Par 
Des Ouvrages de Fondation et de Soutènement En Béton. Guide Pour La Conception, La Realisation et La Maintenance (Zurich, Switzerland, 2005)

37. A. Di Donna, F. Cecinato, F. Loveridge, and M. Barla, Proc. Inst. Civ. Eng.-Geotech. Eng. 170, 232 (2017)

38. J. Zannin, A. Ferrari, M. Pousse, and L. Laloui, Undergr. Space (2020)

39. A. Di Donna and M. Barla, Environ. Geotech. 3, $214(2016)$

40. A. Insana and M. Barla, Renew. Energy 152, 781 (2020)

41. T. Bergman, F. Incropera, A. Lavine, and D. DeWitt, Fundamentals of Heat and Mass Transfer (Wiley, Hoboken, New Jersey, United States, 2011) 42. M. Li and A. C. Lai, Appl. Energy 151, 178 (2015)

43. L. R. Ingersoll, O. J. Zabel, and A. C. Ingersoll, Heat Conduction with Engineering, Geological, and Other Applications (Mc-Graw Hill, New York, United States, 1954)

44. J. Claesson and P. Eskilson, Energy 13, 509 (1988) 45. P. Eskilson, Thermal Analysis of Heat Extraction Boreholes, 1987

46. ASHRAE, ASHRAE Handbook: HVAC

Applications (Atlanta, United States, 2011)

47. H. Carslaw and J. Jaeger, Conduction of Heat in Solids (Oxford University Press, Oxford, United Kingdom, 1959)

48. M. Li and A. C. Lai, Energy 38, 255 (2012)

49. F. Loveridge and W. Powrie, Energy 57, 554 (2013)

50. F. Loveridge and W. Powrie, Geothermics 50, 122 (2014)

51. C. Xia, M. Sun, G. Zhang, S. Xiao, and Y. Zou, Energy Build. 52, 50 (2012)

52. M. Sun, C. Xia, and G. Zhang, Energy Build. 61, $250(2013)$

53. S. Kürten, D. Mottaghy, and M. Ziegler, Acta Geotech. 10, 219 (2015)

54. I. Shafagh, S. Rees, I. Urra Mardaras, M. Curto Janó, and M. Polo Carbayo, Energies 13, 300 (2020)

55. F. Tinti, D. Boldini, M. Ferrari, M. Lanconelli, S. Kasmaee, R. Bruno, H. Egger, A. Voza, and R. Zurlo, Tunn. Undergr. Space Technol. 70, 182 (2017)

56. G. Zhang, C. Xia, M. Sun, Y. Zou, and S. Xiao,

Cold Reg. Sci. Technol. 88, 59 (2013)

57. S. Burlon, J. Habert, F. Szymkievicz, M.

Suryatriyastuti, and H. Mroueh, in Eur. Geotherm.

Congr. (2013), pp. 1-6

58. T. Mimouni and L. Laloui, Acta Geotech. 9, 355 (2014)

59. D. Chen and J. S. McCartney, Int. J. Geomech. 04016159 (2016)

60. E. Ravera, M. Sutman, and L. Laloui, Comput. Geotech. 103294 (2019)

61. C. Garbellini and L. Laloui, Comput. Geotech.

114, 103115 (2019)

62. H. G. Poulos and E. H. Davis, Geotechnique 18, 351 (1968)

63. H. G. Poulos and N. S. Mattes, Géotechnique 19, 285 (1969)

64. R. Butterfield and P. Banerjee, Géotechnique 21, $43(1971)$
65. P. Banerjee and T. Davies, Géotechnique 28, 309 (1978)

66. J. Zannin, A. F. Rotta Loria, Q. Llabjani, and L.

Laloui, Comput. Geotech. Under review (2020)

67. C. Garbellini and L. Laloui, Géotechnique

10.1680/jgeot.19.P.208 (2019)

68. E. Winkler, Die Lehre von Der Elasticitaet Und Festigkeit: Mit Besonderer Rücksicht Auf Ihre

Anwendung in Der Technik Für Polytechnische Schulen, Bauakademien, Ingenieue, Maschinenbauer,

Architecten, Etc (Dominicus, 1867)

69. H. M. Coyle and L. C. Reese, J. Soil Mech. Found. Div 92, (1966)

70. C. Knellwolf, H. Peron, and L. Laloui, J. Geotech. Geoenvironmental Eng. 137, 890 (2011)

71. C. Pasten and J. C. Santamarina, J. Geotech. Geoenvironmental Eng. 140, 06014003 (2014)

72. M. Suryatriyastuti, H. Mroueh, and S. Burlon, Comput. Geotech. 55, 378 (2014)

73. M. Sutman, C. G. Olgun, and L. Laloui, J.

Geotech. Geoenvironmental Eng. 145, 04018101 (2019)

74. C. Iodice, R. D. Laora, and A. Mandolini, J.

Geotech. Geoenvironmental Eng. 146, 04020016 (2020)

75. E. Ravera, M. Sutman, and L. Laloui, J. Geotech.

Geoenvironmental Eng. 146, 04020042 (2020)

76. H. G. Poulos and E. H. Davis, Pile Foundation Analysis and Design (Wiley, New York, 1980)

77. A. F. Rotta Loria and L. Laloui, Comput. Geotech. 80, 121 (2016)

78. A. F. Rotta Loria and L. Laloui, Comput. Geotech. 90, 144 (2017)

79. A. F. Rotta Loria, A. Vadrot, and L. Laloui, Geomech. Energy Environ. 16, 1 (2018)

80. H. G. Poulos and N. S. Mattes, J. Geotech.

Geoenvironmental Eng. 100, 185 (1974)

81. H. G. Poulos, CE Trans Inst Engrs Aust. CE10 2 $206(1968)$

82. E. H. Davis and H. G. Poulos, Aust. Geotech. J. 2, 21 (1972)

83. H. G. Poulos, Géotechnique 18, 449 (1968)

84. R. D. Mindlin, J. Appl. Phys. 7, 195 (1936)

85. Y. Chow, Int. J. Numer. Anal. Methods Geomech. 10, 59 (1986)

86. A. F. Rotta Loria, A. Vadrot, and L. Laloui, Comput. Geotech. 86, 9 (2017)

87. H. G. Poulos, J. Geotech. Eng. 114, 697 (1988)

88. A. F. Rotta Loria and L. Laloui, Géotechnique 67, 691 (2017)

89. M. F. Randolph and C. P. Wroth, J. Geotech. Eng. Div. 104, 1465 (1978)

90. M. Randolph and C. Wroth, in Behav. Deep

Found. (ASTM International, 1979)

91. Y. Chow, Comput. Struct. 24, 157 (1986)

92. M. Randolph and P. Clancy, in edited by V. Impe

(Balkema, Rotterdam, 1993), pp. 119-130

93. M. Randolph, in XIII Int. Conf. Soil Mech.

Geotech. Eng. (1994), pp. 61-82

94. K. Lee and Z. Xiao, Can. Geotech. J. 38, 1063 (2001)

95. A. Di Donna and L. Laloui, Int. J. Numer. Anal.

Methods Geomech. 39, 861 (2014)

96. F. Dupray, C. Li, and L. Laloui, Acta Geotech. 9, $413(2014)$ 
97. A. F. Rotta Loria, A. Gunawan, C. Shi, L. Laloui, and C. W. Ng, Geomech. Energy Environ. 1, 1 (2015) 98. A. F. Rotta Loria, A. Di Donna, and L. Laloui, J. Geotech. Geoenvironmental Eng. 141, 04015042 (2015) 99. A. Di Donna, A. F. Rotta Loria, and L. Laloui, Comput. Geotech. 72, 126 (2016)

100. S. Abdelaziz and T. Y. Ozudogru, Environ. Geotech. 3, 237 (2016)

101. N. Batini, A. F. Rotta Loria, P. Conti, D. Testi, W. Grassi, and L. Laloui, Appl. Therm. Eng. 86, 199 (2015) 102. F. Cecinato and F. A. Loveridge, Energy 82, 1021 (2015)

103. K. A. Gawecka, D. M. Taborda, D. M. Potts, W. Cui, L. Zdravković, and M. S. Haji Kasri, Proc. Inst. Civ. Eng.-Geotech. Eng. 1 (2016)

104. M. Barla, A. Di Donna, and A. Perino, Geothermics 61, 104 (2016)

105. P. Buhmann, B. Westrich, C. Moormann, A. Bidarmaghz, and G. Narsilio, in (2016), pp. 601-605 106. D. Sterpi, A. Coletto, and L. Mauri, Geomech. Energy Environ. 9, 1 (2017)

107. O. Ogunleye, R. M. Singh, F. Cecinato, and J. Chan Choi, Renew. Energy 146, 2646 (2020)

108. A. Bidarmaghz and G. A. Narsilio, Geomech.

Energy Environ. 16, 83 (2018)

109. B. Cousin, A. F. Rotta Loria, A. Bourget, F. Rognon, and L. Laloui, Tunn. Undergr. Space Technol. 91, 102997 (2019)

110. C. G. Olgun, T. Y. Ozudogru, S. L. Abdelaziz, and A. Senol, Acta Geotech. 10, 553 (2015)

111. A. Bidarmaghz, G. A. Narsilio, I. W. Johnston, and S. Colls, Geomech. Energy Environ. 6, 35 (2016) 112. T. Bodas Freitas, F. Cruz Silva, and P. BourneWebb, in 18th Int. Conf. Soil Mech. Geotech. Eng. (Comité Français de Mécanique des Sols et de Géotechnique, 2013), pp. 3347-3350

113. A. Mortada, R. Choudhary, and K. Soga, J. Build. Perform. Simul. 11, 517 (2018)

114. J. Epting, M. Baralis, R. Künze, M. H. Mueller, A. Insana, M. Barla, and P. Huggenberger, Geothermics 83, 101734 (2020)

115. M. Barla and A. Di Donna, Undergr. Space 3, 268 (2018)

116. S. Kürten, D. Mottaghy, and M. Ziegler, Energy Build. 107, 434 (2015)

117. A. Bidarmaghz, G. A. Narsilio, P. Buhmann, C. Moormann, and B. Westrich, Geomech. Energy Environ. 10, 29 (2017)

118. Y. Rui and M. Yin, Can. Geotech. J. 55, 720

(2017)

119. D. Rammal, H. Mroueh, and S. Burlon, Renew.

Energy 147, 2643 (2020)

120. D. Sterpi, G. Tomaselli, and A. Angelotti, Renew. Energy 147, 2748 (2018)

121. N. Makasis, G. A. Narsilio, A. Bidarmaghz, I. W. Johnston, and Y. Zhong, Comput. Geotech. 120, 103399 (2020)

122. J. Claesson and S. Javed, ASHRAE Trans. 118,

530 (2012)

123. M. I. Gorbunov-Posadov and R. V. Serebrjanyi, in 5th Int. Conf. Soil Mech. Found. Eng. (1961), pp. 643648
124. A. F. Rotta Loria, J. V. Català Oltra, and L. Laloui, Comput. Geotech. 120, 103410 (2020)

125. M. Sutman, G. Olgun, L. Laloui, and T. Brettmann, in Geotech. Front. 2017 (2017), pp. 165-174

126. P. J. Bourne-Webb, Comput. Geotech. 118, 103309 (2020)

127. F. Dupray, L. Laloui, and A. Kazangba, Comput. Geotech. 55, 67 (2014)

128. E. Sailer, D. M. Taborda, and L. Zdravković, Renew. Energy 118, 579 (2018)

129. E. Sailer, D. M. Taborda, L. Zdravković, and D. M. Potts, Proc. Inst. Civ. Eng.-Geotech. Eng. 1 (2020)

130. A. F. Rotta Loria, F. Orellana, A. Minardi, J.-M. Furbringer, and L. Laloui, Comput. Geotech. 69, 485 (2014)

131. J. E. Bowles, Foundation Analysis and Design (McGraw-Hill, Singapore, 1988)

132. K. Fleming, A. Weltman, M. Randolph, and K. Elson, Piling Engineering (CRC press, 2008)

133. D. Salciarini, F. Ronchi, E. Cattoni, and C. Tamagnini, Int. J. Geomech. 15, 04014042 (2015) 134. D. Salciarini, F. Ronchi, and C. Tamagnini, Acta Geotech. 12, 703 (2017)

135. T. Y. Ozudogru, C. G. Olgun, and C. F. Arson, Geotech. Geol. Eng. 33, 357 (2015)

136. R. Saggu and T. Chakraborty, Geomech.

Geoengin. 10, 10 (2015)

137. M. Adinolfi, R. M. S. Maiorano, A. Mauro, N. Massarotti, and S. Aversa, Geomech. Energy Environ. 16, 32 (2018)

138. E. Sailer, D. M. Taborda, L. Zdravković, and D. M. Potts, Comput. Geotech. 109, 189 (2019)

139. R. Saggu and T. Chakraborty, Int. J. Geomech. 16, 04015100 (2016)

140. A. Vieira and J. R. Maranha, Int. J. Geomech. 17, 04016030 (2016)

141. C. J. R. Coccia and J. S. McCartney, Comput.

Geotech. 80, 16 (2016)

142. P. Bourne-Webb, T. Bodas Freitas, and R. Freitas Assunção, Géotechnique 66, 167 (2016)

143. A. F. Rotta Loria and L. Laloui, in First Int. Conf. Energy Geotech. ICEGT 2016 (CRC Press, 2016), pp. $171-178$

144. M. Suryatriyastuti, S. Burlon, and H. Mroueh, Int. J. Numer. Anal. Methods Geomech. 40, 3 (2015)

145. C. W. W. Ng, Q. J. Ma, and A. Gunawan, Comput. Geotech. 78, 54 (2016)

146. T. Lambe, Géotechnique 23, 151 (1973) 